\title{
ESTRATÉGIA DE INTERVENÇÃO NA GESTÃO DE INOVAÇÃO DE PRODUTOS EM PMES: CASO FIRMAS DE FUNDIÇÃO
}

\section{INTERVENTION STRATEGY ON SMES'S PRODUCT INNOVATION MANAGEMENT: CASE OF FOUNDRY FIRMS}

\author{
Leonel Del Rey de Melo Filho ${ }^{1}$; Carlos Alberto Gonçalves ${ }^{2}$; Lin Chih Cheng ${ }^{3}$; Lauro Soares de \\ Freitas $^{4}$ \\ ${ }^{1}$ Universidade Federal de Minas Gerais - CEPEAD - MG - Brasil \\ leoneldrmf@yahoo.com.br \\ ${ }^{2}$ Universidade Federal de Minas Gerais - CEPEAD - MG - Brasil \\ carlos@face.ufmg.br \\ ${ }^{3}$ Universidade Federal de Minas Gerais - MG - Brasil \\ lincheng@ufmg.br \\ ${ }^{4}$ Universidade Federal de Minas Gerais - CEPEAD - MG - Brasil \\ lauro_freitas@yahoo.com
}

\begin{abstract}
Resumo
$O$ objetivo deste artigo é apresentar a aplicação de um framework e seu procedimento de intervenção referentes a um estudo que buscou avaliar práticas gerenciais de inovação de produtos, com foco naquelas configuradas como Capacidades Dinâmicas (CD). A estratégia de formulação e implantação das intervenções baseou-se na perspectiva da Visão Baseada em Recursos e nas Capacidades Dinâmicas, por meio do estudo e aplicação de métodos configurados. Seis firmas de fundição da região centro oeste de $M G$ foram estudadas ao longo de um mesmo programa de intervenção para introdução de práticas gerenciais. A abordagem metodológica utilizada foi a pesquisa-ação, a qual foi associada com a aplicação de diferentes métodos de coleta de dados (ex. protocolo de busca e armazenamento de informações, análise de documentação e entrevista estruturada). Os resultados mostraram que o programa contribuiu para a implantação de práticas gerenciais de inovação de produtos, sendo estas adaptadas às contingências organizacionais relacionadas com as CDs detecção, apreensão e reconfiguração tecnológica. Durante o programa, em função do uso das novas práticas, algumas PMEs conseguiram desenvolver e lançar com maior sucesso novos produtos, enquanto outras apresentaram melhorias das respectivas rotinas organizacionais, dentre outros resultados qualitativos.
\end{abstract}

Palavras-chave - Intervenção; Capacidades Dinâmicas; Gestão da Inovação de Produtos; PMEs.

\section{Introdução}

Gestores têm buscado compreender quais fatores fazem determinadas firmas possuírem vantagens competitivas em relação a competidores localizados em mercados concorrenciais, uma vez que necessitam de um referencial para ações que lhes permitam a sobrevivência, crescimento e 
prosperidade nos negócios em que atuam (HITT et al, 2007). Tais fatores são responsáveis pela idiossincrasia das firmas (PENROSE, 1959; NELSON e WINTER, 1982) e, consequentemente, pela diferença de desempenho das mesmas.

Resultados de pesquisas mostram que firmas que competem em mercados concorrenciais e investem em inovação tendem a obter retornos mais elevados (HITT et al, 2007). A inovação destina-se a aumentar a competitividade estratégica, sendo um recurso essencial que impacta diretamente no desempenho da firma, além de influenciar a mudança social e econômica de regiões (KIM e HUARNG, 2011; SARACENI et al, 2013). As firmas que são capazes de inovar consistentemente e efetivamente estão bem posicionadas para utilizar tais habilidades como uma vantagem competitiva (HITT et al, 2007). Crossan e Apaydin (2010) definem inovação como:

“[...] a produção ou adoção, assimilação e exploração (exploitation) de um valor acrescentando-se novidade nas esferas econômica e social; renovação e ampliação de produtos, serviços e mercados; o desenvolvimento de novos métodos de produção; e criação de novos sistemas de gestão. É um processo e um resultado".

Para o escopo deste trabalho foi considerada a gestão da inovação como ambidestra (LIN et al, 2013), radical e incremental "realmente nova", podendo ser nova para uma linha de produtos, nova para empresa e pouco ou sem nenhuma novidade para o mercado.

Em um mercado concorrencial em que a capacidade de inovação figura como diferencial competitivo, tem-se, por um lado, grandes firmas com vantagens relacionadas a esta, tais como: marcas de renome, ganhos em escala, maior influência sobre contratos, maior acesso a informações, infraestrutura, centros de pesquisa, mão de obra qualificada e métodos de gestão que permitem uma melhor garantia da qualidade dos novos produtos e produtividade dos novos processos de manufatura (YUSOF e ASPINWALL, 2000; SABRAGIA e STAL, 2002). Mesmo parecendo não favorável este cenário, há uma tendência à manutenção ou mesmo crescimento do número de PMEs que possuem algumas vantagens em relação às grandes firmas, como maior flexibilidade, informalidade e velocidade na tomada de decisão e menor resistência a mudanças (NICHOLAS et al, 2011).

A inovação de produto e processo tem uma positiva e forte relação com o desempenho de PMEs (AR e BAKI, 2011). Segundo Rammer et al (2009), um dos fatores que impactam positivamente neste desempenho é o uso efetivo de métodos de gestão da inovação. Segundo Kaminski et al (2005), em geral as PMEs brasileiras ainda são carentes de conhecimentos relacionados à gestão da inovação de produtos o que às coloca em desvantagem no mercado global.

Segundo a OCDE (2004), para que uma PME seja inovadora ela precisa ter acesso a fontes externas de informação, conhecimento, know-how e tecnologia para que possa construir suas próprias capacidades. A aquisição de conhecimentos e competências por meio da colaboração externa é uma maneira eficiente para o sucesso das inovações das PMEs (KAMINSKI et al, 2008). 
Neste cenário é importante que organizações de apoio empresarial (OAE; ex. SEBRAE e FIEMG) e institutos de ciência e tecnologias (ICTs) desenvolvam programas estratégicos que auxiliem o aprendizado de PMEs em tecnologias de gestão de inovação de produtos. A literatura é profícua em mostrar intervenções externas em grandes empresas, no entanto, casos em PMEs ainda não são tão comuns (ASSARLIND et al, 2013).

Em 2007 uma OAE de MG entrou em contato com pesquisadores da UFMG e solicitou o desenvolvimento de um programa empresarial para capacitar gestores de PMEs no uso de métodos da gestão de inovação de produtos. O objetivo desse artigo é apresentar um framework e seus procedimentos de intervenção na gestão de inovação de produtos, tendo como base um caso de PMEs industriais de MG. Seis firmas de fundição da região centro oeste de MG foram pesquisadas ao longo de um mesmo programa de intervenção, o qual tinha como fim a introdução de práticas gerenciais de gestão da inovação. A estratégia de pesquisa adotada foi a pesquisa-ação e, alguns resultados alcançados foram: desenvolvimento e aplicação de um programa de implantação de práticas gerenciais de inovação de produtos, relacionadas com as CDs de detecção, apreensão e reconfiguração tecnológica; algumas PMEs conseguiram desenvolver e lançar com sucesso novos produtos, enquanto outras apresentaram melhorias das respectivas rotinas organizacionais.

$\mathrm{O}$ artigo possui uma breve revisão da literatura sobre intervenção em PMEs em métodos de gestão, mudança organizacional e intervenção, atividades da intervenção em PMEs, VBR e Capacidades dinâmicas com foco na rotina de inovação e sistema de gestão de inovação de produtos. Logo em seguida apresenta-se uma descrição da metodologia, resultados alcançados, análises e conclusões.

\section{Intervenção em PMEs em métodos de gestão}

Intervenções são utilizadas para auxiliar PMEs na introdução de práticas gerenciais consideradas de sucesso (ex. ACHANGA et al, 2006; DONE et al, 2011; KUMAR et al 2011; GARENGO e BIAZZO, 2012; ASSARLIND et al, 2013). A introdução de formas inovadoras de trabalho é geralmente um processo difícil para as PMEs (SHAH, 2003), cujos benefícios de curto prazo devem ser definidos, embora seja uma jornada de longo prazo. No entanto, os resultados de sucesso de curto prazo podem ser uma contribuição importante para a visibilidade e aceitação das novas práticas ao longo do tempo (DONE et al, 2011).

Segundo Done et al (2011), evidências indicam que grandes firmas são mais susceptíveis a possuir os recursos necessários para implementação de melhores práticas. Por outro lado, países são propelidos a desenvolverem e implementarem programas de intervenção com financiamento público voltados especificamente para auxílio às PMEs. Assarlind et al (2013) relataram que uma maneira usual de PMEs entrarem em contato com novas formas de trabalho é por meio de algum 
tipo de intervenção externa. A falta de recursos das PME não só se manifesta pela ausência ou escassez de dinheiro, mas também na escassez de agentes de mudanças internos que possuem conhecimento sobre as melhores práticas e know-how em processos de mudança (ASSARLIND et al, 2013). Uma maneira de resolver este problema é por meio de intervenções externas como forma de apoio à mudança (DONE et al, 2011; ASSARLIND et al, 2013).

A intervenção em melhores práticas de gestão pode ser definida como uma atividade destinada a introduzir novas práticas na organização por meio de uma série de ações focadas de curta duração (DONE et al, 2011). De forma similar, Assarlind et al (2013) definiram a intervenção em práticas de gestão como atividades que objetivam a introdução de novas formas de trabalho por meio de uma série de ações focadas nas organizações.

A literatura é profícua no relato de intervenções em práticas relacionadas com as áreas de qualidade e estratégia, como TQM, ISO 9000 (ex. PRAJOGO e BROWN, 2006), Lean Manufacturing (ex. ACHANGA et al, 2006), Six Sigma (ex. KUMAR et al 2011), BSC (GARENGO e BIAZZO, 2012), entre outras. No entanto, relatos sobre intervenção na gestão de inovação de produtos em PMEs industriais são raros. Nicholas et al (2011) mostraram que as PMEs podem ganhar vantagem competitiva sobre os concorrentes por meio do uso de estratégias que empregam práticas de inovação tipicamente utilizadas por grandes empresas, como processos formais de inovação de produtos, se devidamente adaptadas às suas contingências.

\section{Mudança organizacional e intervenção}

O propósito estratégico de qualquer intervenção é promover mudanças nas firmas para que possam alcançar melhores desempenhos e vantagens competitivas no curto e longo prazo. Segundo Burnes (2004a), a mudança é uma característica sempre presente na vida das firmas, a qual não pode ser separada da estratégia organizacional, ou vice-versa. A mudança organizacional pode ser definida como um processo de renovação do direcionamento, estrutura e capacidades de uma organização para atendimento das necessidades dos clientes externos e internos que mudam constantemente (MORAN e BRIGHTMAN, 2001); além de poder ser vista em diferentes perspectivas (PETTIGREW, 2012; ASSARLIND et al, 2013) complementares e observadas em diferentes contextos, como as abordagens das mudanças planejadas e emergentes (BURNES, 1996; BAMFORD e FORRESTER, 2003; BY, 2005).

A primeira mostra ser eficaz em ambientes estáveis, enquanto a segunda tende a tratar a mudança como conduzida de baixo para cima, sugerindo ela é um processo aberto e contínuo de adaptação às novas condições ambientais (BURNES, 1996). Segundo By (2005), enquanto a abordagem da mudança planejada é vista como uma série de eventos lineares dentro de um 
determinado período de tempo, na abordagem emergente a mudança é vista como um processo contínuo, aberto e adaptativo a novas circunstâncias e condições.

Beer e Nohria (2000) apresentaram outra perspectiva teórica sobre a mudança organizacional. Segundo eles, a mudança estratégica pode ser explicada por duas teorias: E e O. A primeira envolve pesados usos de incentivos econômicos, sendo que a ênfase encontra-se na mudança da estrutura e sistema, o processo é baseado em planejamento e programas estabelecidos e o agente da mudança (ex. consultores ou pesquisadores) enfatiza a análise de problemas e elaboração de soluções. Já na Teoria $\mathrm{O}$ o objetivo principal é a mudança das capacidades organizacionais, sendo caracterizada pelo foco no desenvolvimento de cultura, pelo processo baseado no envolvimento e experimentação, e pelo agente da mudança apoiar-se na gestão relacionada à prática de suas próprias soluções. Contudo, os mesmos autores argumentam que a combinação das abordagens seria a maneira mais eficaz de promover mudanças.

Pettigrew (1987) destaca que um ponto inicial para o trabalho de mudança estratégica seria a noção de que a formulação do conteúdo inevitavelmente implicaria na gestão de seu contexto e processo. Armenakis e Bedeian (1999) e Pettigrew (2012) acrescentam ao modelo os resultados objetivados e alcançados durante e após o processo de mudança organizacional, os quais podem ser de curto ou longo prazo, e ainda podem ser usados para analisar o porquê da mudança.

Segundo Pettigrew (1987), a razão para a mudança emana principalmente do contexto externo. Oakland e Tanner (2007) concluíram em sua pesquisa que firmas foram induzidas à mudança principalmente em função de direcionadores estratégicos externos. Os direcionadores internos foram considerados como manifestação dos externos.

Alguns autores propõem fatores de sucesso para a mudança organizacional em geral, como Kotter (1995) e Oakland e Tanner (2007). Mais recentemente, outros propuseram um conjunto semelhante de fatores, mas com a abordagem de intervenções externas aplicáveis às PMEs, como Done et al (2011) e Assarlind et al (2013). Done et al (2011) apresentam um quadro de onze proposições que influenciam o sucesso no curto prazo e a sustentabilidade a longo prazo das intervenções. Estas proposições foram agrupadas em: contexto da intervenção; formulação e implementação da intervenção e; abordagem do agente da mudança (Quadro 1).

Quadro 1 - Fatores que influenciam o sucesso no curto prazo e sustentabilidade a longo prazo das intervenções

\begin{tabular}{|l|l|}
\hline \multicolumn{1}{|c|}{ Dimensões } & \multicolumn{1}{c|}{ Fatores } \\
\hline \multirow{4}{*}{ Contexto da intervenção } & Estratégia e objetivos para a mudança claramente comunicados \\
\cline { 2 - 2 } & Prontidão organizacional para a mudança \\
\cline { 2 - 2 } & Indicadores de desempenho alinhados aos objetivos do programa de mudança \\
\cline { 2 - 2 } & Recompensa e reconhecimento dos resultados positivos no curto prazo \\
\hline \multirow{4}{*}{$\begin{array}{l}\text { Formulação e } \\
\text { implementação da } \\
\text { intervenção }\end{array}$} & Adaptação do processo e conteúdo da intervenção ao contexto específico \\
\cline { 2 - 2 } & Organização e disponibilização de recursos (financeiros, humanos e físicos) \\
\cline { 2 - 2 } & Bom gerenciamento da implementação da intervenção \\
\cline { 2 - 2 } & Gerenciamento das expectativas das partes interessadas (stakeholders) \\
\cline { 2 - 2 } & Desenvolvimento de facilitadores internos (“Champion") \\
\hline
\end{tabular}




\begin{tabular}{|l|l|}
\hline $\begin{array}{l}\text { Abordagem do agente } \\
\text { da mudança }\end{array}$ & Conhecimentos gerais e competências do agente da mudança \\
\cline { 2 - 2 } & Plano pós-intervenção para suporte do agente às atividades em curso \\
\hline
\end{tabular}

Fonte: Done et al (2011).

No trabalho de Done et al (2011), os momentos temporais de obtenção de resultados da intervenção foram divididos em: pré-intervenção - nível de desempenho operacional observado antes da intervenção; curto prazo - imediatamente após a intervenção; médio prazo - meio ano após a intervenção; longo prazo - após 1 ano da intervenção.

Assarlind et al (2013) acrescentaram três proposições adicionais ao quadro de Done et al (2011), as quais estão relacionadas ao conteúdo de uma intervenção: suportar a formulação de estratégias, incentivar o diálogo, e utilizar dados das firmas. A seguir são relatadas atividades relacionadas com a formulação e o processo de intervenção.

\section{Atividades da intervenção em PMEs}

A forma de realização das atividades de intervenção está relacionada com as competências e comportamento dos agentes da mudança (DONE et al, 2011). Dependendo da experiência do agente externo, as firmas podem tomar ações e rotas diferentes, o que condiciona o resultado em função da personalidade e conhecimento do facilitador (ASSARLIND et al, 2013). Assarlind et al (2013) relatam que os resultados da intervenção dependem diretamente das características, dedicação, comprometimento, decisões e ações da equipe da firma. Geralmente os envolvidos não são deslocados para trabalharem somente nas atividades relacionadas com a intervenção, o que divide suas atenções com as demandas de suas rotinas diárias (DONE et al, 2011).

Segundo Done et al (2011), as intervenções externas geralmente consistem de: (1) atividades de preparação; (2) um ou mais workshops de melhoria (geralmente menos de uma semana cada workshop); (3) eventos de encerramento; (4) acompanhamento das atividades práticas. Esses autores estudaram intervenções cujo propósito fora implantar práticas de manufatura enxuta em PMEs.

Pesquisadores têm formulado frameworks/modelos e processos teóricos de implantação de práticas gerenciais utilizadas como conteúdos base no processo de intervenções em PMEs, as quais são adaptadas às contingências das firmas. Kumar et al (2011) apresentam um framework de 5 passos para implantação do Six Sigma: prontidão, preparação, inicialização, institucionalização e sustentação. Yusof e Aspinwall (2001) apresentam um framework de 4 grandes blocos para a implantação do sistema TQM em PMEs, que são: (a) comitê de coordenação; (b) iniciativas de qualidade, composto por um conjunto de métodos e técnicas de gestão; (c) metodologia geral composta pelas etapas de planejamento, educação/treinamento, teste piloto, revisão, melhoria e padronização e; (d) desdobramento da estratégia, alocação de recursos, acompanhamento do 
processo e métodos técnicas complementares. Esses autores apresentaram casos de utilização e adaptação deste framework.

No entanto, processos de intervenção e frameworks de implantação de métodos e técnicas da gestão de inovação de produtos (GIP) em PMEs são escassos. No Brasil, trabalhos sobre este tema são recentes. Kaminski et al $(2005 ; 2008)$ realizaram um estudo sobre o uso de ferramentas da GIP em PMEs do setor metal-mecânico do estado de São Paulo, no qual como resultado a noção de que as firmas não faziam o uso de técnicas da GIP consagradas em grandes firmas, se restringindo principalmente ao uso do CAD.

Este artigo pretende contribuir para o preenchimento desta lacuna teórica. Para elaboração do framework base do conteúdo e processo da intervenção, os pesquisadores utilizaram a perspectiva estratégica das Capacidades Dinâmicas, e a configuração de métodos da gestão de inovação de produtos.

\section{VBR e Capacidades Dinâmicas: foco rotina de inovação}

No enfoque pela Visão Baseada nos Recursos (VBR), as firmas, independente de oferecerem produtos com relativa equivalência nos mercados, podem ser diferenciadas na forma de gerir seus recursos tangíveis e, notadamente, os intangíveis (BARNEY, 1991). A firma é "vista" pelos resultados obtidos de suas operações, pelas suas resultantes e também pelas potencialidades e restrições de gestão de seus recursos (CARVALHO et al, 2011).

A teoria da VBR preconiza que o crescimento da firma é explicado notadamente pela capacidade de gestão competente dos recursos internos (BARNEY, 1991; LOCKETT, THOMPSON e MORGENSTERN, 2009). Aqui considera-se que as firmas são diferenciadas pelos seus recursos e que a forma de gestão introduz diferenças significativas entre elas (PENROSE, 1959). Nesse sentido, quando uma firma desenvolve habilidades internas, permite-se o alcance de vantagens competitivas para obtenção de oportunidades do ambiente externo (BARNEY e CLARCK, 2007). Nessa forma de agir, a abstração dominante é a "visão de dentro para fora da firma" em primeira instância (HOSKISSON et al, 1999).

De acordo com Gonçalves et al (2011), cinco construtos ênfases dão sentido à experiência estratégica da firma: (1) cultura organizacional orientada para a competitividade; (2) gestão do conhecimento e inovação em ritmo dinâmico; (3) busca de geração de vantagem competitiva sustentável; (4) inteligência competitiva e finalmente (5) "tônus" estratégico e empreendedorismo.

Uma linha teórica oriunda da VBR enfatiza as habilidades organizacionais chamadas de Capacidades Dinâmicas como responsáveis pela idiossincrasia do desempenho das firmas (TEECE et al, 1997; AMBROSINI e BOWMAN, 2009). 
Capacidades são os processos de gestão necessários para "moldar os recursos" de modo a gerar alguma vantagem (TEECE et al, 1997). As capacidades dinâmicas refletem as habilidades organizacionais em ativar formas inovadoras de vantagem competitivas.

Zollo e Winter (2002) chamaram os processos codificáveis passíveis de repetição e generalizáveis como "blocos de construção para o desenvolvimento de uma capacidade dinâmica". Para eles, a rotina é um padrão aprendido e estável de atividades coletivas por meio das quais as organizações sistematizam, geram e modificam suas atividades operacionais em busca de maior desempenho. Assim, as rotinas não são estáticas, mas sim um processo de padronização e modificação constantes.

Com um enfoque na inovação, Helfat (1997) define as capacidades dinâmicas como um subconjunto de capacidades que permitem à firma criar novos produtos, processos e a responder às condições de mercado em constante mudança. Segundo Eisenhardt e Martin (2000), as CD são processos estratégicos e organizacionais integrados às firmas (ex. inovação de produtos e tomada de decisão).

Neste contexto, pode-se definir que os processos (métodos) organizacionais relacionados com a rotina de inovação de produtos são capacidades dinâmicas. Sob esta mesma perspectiva, O’Connor (2008) relata que as rotinas de inovação são capacidades dinâmicas compostas por diferentes elementos. Ambrosini e Bowman (2009) relatam que a gestão de inovação de produto pode ser vista como capacidades dinâmicas reais por permitir a renovação e reconfiguração de recursos de uma firma.

Teece (2007) apresentou uma explicação sobre a natureza e os microfundamentos das capacidades dinâmicas, os quais seriam: habilidades distintivas, sistemas, processos, procedimentos, estruturas organizacionais, regras de decisão e, são desagregadas nos blocos: I - detecção (“dar sentido, percepção e formatação") das oportunidades e ameaças; II - apreensão para aproveitar as oportunidades; III - manutenção da competitividade por meio da melhoria, combinação, proteção e, quando necessário, reconfiguração dos ativos tangíveis e intangíveis do negócio da organização.

A formulação e implementação da intervenção, bem como o desenvolvimento do framework base de métodos e técnicas da GIP, foram realizados sob a perspectiva de que as PMEs deveriam melhorar suas capacidades dinâmicas para obter os resultados desejados.

\section{Sistema de gestão de inovação de produtos - perspectiva de métodos configurados}

Um sistema de inovação de produtos (SIP) pode ser compreendido pelo esquema de entrada (ideias), processamento e saída (produtos no mercado), envolto pelo ambiente externo de mercado e tecnologia (CHENG e MELO FILHO, 2010). A gestão deste sistema refere-se ao conjunto de processos, tarefas e atividades de planejamento, organização, decisão e ação dos envolvidos para 
que resultados de sucesso sejam alcançados. Associado a isso, é fator de sucesso saber integrar os diversos agentes, tanto externos (ex. parcerias, fornecedor e cliente), quanto internos (ex. áreas funcionais), de forma a trabalharem cooperativamente envidando ao sistema os esforços de competências grupais em conceitos e métodos.

Este sistema possui pelo menos dois níveis de gestão: programa e operacional, cujos alinhamentos à estratégia da firma são fatores de sucesso (MONTOYA-WEISS e CALANTONE, 1994). Segundo Milles et al (1978) as firmas possuem quatro posicionamentos estratégicos de inovação: pioneiras, analisadoras, defensoras e reativas. No nível operacional podem existir duas estratégias do desenvolvimento de produtos: imitação e inovação para o mercado. A primeira pode ser subdivida em: falsificações (piratarias), cópias, imitação reprodutiva, imitação de design e imitação criativa (SCHNAARS, 1994).

A aplicação de métodos e técnicas (ex. processo de desenvolvimento e gestão de portfólio), bem como a organização do trabalho em ambos os níveis de gestão, são alguns dos fatores de sucesso (BARCZAK et al, 2009). Uma perspectiva utilizada por pesquisadores e práticos é a gestão do SIP por meio de métodos configurados em uma relação de causa-e-efeito integrada a processos (ex. MORGAN e LIKER, 2006; CHENG e MELO FILHO, 2010). Os métodos de trabalho utilizados nesta pesquisa foram: Roadmapping (PHAAL et al, 2010), Gestão de Plataformas (MEYER; LEHNERD, 1997; MEYER; DALAL, 2002), Gestão de Portfólio (Cooper et al 1998), Processo de Desenvolvimento de Produtos (PDP) (COOPER, 2008; ULRICH e EPPINGER, 2012) e Método QFD (CHENG e MELO FILHO, 2010).

O método QFD foi acrescentado ao conteúdo em função de trabalhos mostrarem que, quando utilizado como compreehensive, é um método estruturador que integra a busca de conhecimentos com métodos relevantes para o processo de robustecimento do sistema de desenvolvimento de produtos de firmas (CHENG e MELO FILHO, 2010). Este método engloba o desdobramento do trabalho (QFDr) (MELO FILHO e CHENG, 2010), o qual equivale às etapas e atividades do PDP e organização do trabalho. Assim, no framework construído o QFDr esta representado pelo PDP e pela organização do trabalho, enquanto o QD (desdobramento das informações) está representado pelas unidades operacionais do QFD (tabelas, matrizes, modelo conceitual e padrões). Também foi acrescentado a este conteúdo ferramentas estatísticas que poderiam ser utilizadas em conjunto com o método. Neste caso, na etapa de projeto detalhado do produto e processo, pode-se utilizar a matriz de características de qualidade do produto final (CQPF) versus o parâmetro de controle do processo (PCP) em conjunto com a ferramenta estatística de planejamento e análise de experimentos para melhor projetar os parâmetros do processo e especificação do produto (ex. MELO FILHO e CHENG, 2007). 
Para elaboração do framework, utilizaram-se princípios do pensamento e desenvolvimento enxuto. Segundo Womack e Jones (2003), para implantação de um sistema de gestão básico, devese desenvolver as seguintes atividades: (I) estabelecer um fluxo de trabalho; (II) atribuir às etapas do fluxo os itens em processo (ex. classificar os produtos nas suas etapas de desenvolvimento); (III) fazer os itens fluírem naturalmente no fluxo; (IV) promover um sistema puxado pelas necessidades de mercado; e (V) realizar melhoria contínua. Morgan e Liker (2006) relatam que os itens básicos de um sistema de desenvolvimento de produtos são pessoas, processo e ferramentas e tecnologias, os quais deveriam ser integrados. Estes autores acrescentaram a importância de se alinhar a organização em uma simples comunicação visual (i.e. gestão a vista).

\section{Abordagem metodológica}

A estratégia de pesquisa adotada foi a pesquisa-ação, adequada quando se necessita a intervenção do pesquisador e o levantamento de fatores importantes para $\mathrm{o}$ trabalho (CHECKLAND, 1999; THIOLLENT, 1997). Segundo BURNES (1996; 2004b), esta abordagem é adequada para trabalhos em que o pesquisador participa da mudança organizacional. A pesquisaação permite a geração de conhecimentos que preenche algumas lacunas da ciência funcionalista e contribui na solução de problemas teóricos e práticos de interesse tanto de pesquisadores quanto de gerentes (SUSMAN \& EVERED, 1978).

Esta estratégia "acopla" a pesquisa e ação em um processo no qual os atores da situação (membros representativos da situação investigada) participam, junto com os pesquisadores, para elucidar, de forma interativa, a realidade na qual estão inseridos, identificando problemas coletivos e buscando e experimentando soluções em situação real. Seu princípio fundamental consiste na intervenção dentro da organização, a partir da qual seus membros e pesquisadores colaboram na definição do problema, na busca de soluções e, simultaneamente, no aprofundamento do conhecimento científico (THIOLLENT, 1997).

O conhecimento sobre o que é a pesquisa-ação e seus procedimentos operacionais já foi descritos e detalhados por diversos autores (ex. COUGHLAN e COGHLAN, 2002; WESTBROOK, 1995; SUSMAN e EVERED, 1978; RAPOPORT, 1970). Os pesquisadores geralmente procuraram não lidar com hipóteses, mas com temas de pesquisa ou proposições pelos quais aprendizados práticos e teóricos podem ser obtidos ao longo e após a mudança organizacional (CHECKLAND e HOLWELL, 1998).

Em linhas gerais, a condução da pesquisa-ação segue sempre cinco grandes fases: diagnóstico inicial (identificação ou definição do problema de pesquisa), planejamento da ação, implementação (ação), avaliação (observação) dos resultados e especificação do aprendizado 
(reflexão) (THIOLLENT, 1997; SUSMAN \& EVERED, 1978; ZUBER-SKERRITT e PERRY, 2002).

Os métodos de pesquisa utilizados para coleta de dados foram: anotações dos pesquisadores, protocolo de busca de informações (YIN, 2005), observação direta, entrevistas estruturadas e análise de documentos internos: planilhas e procedimentos de gestão, relatórios e atas de reuniões. Realizou-se uma pesquisa longitudinal por meio da coleta de dados ao longo e no final da intervenção, como também após alguns meses do término das atividades. A Figura 1 resume a abordagem metodológica. O Quadro 2 caracteriza as firmas pesquisadas.

Figura 1 - Abordagem metodológica

Estratégia de pesquisa: Pesquisa-Ação

Métodos de coleta de dados

- Entrevistas estruturadas, protocolo de busca de informações, análise de documentos internos, anotações dos pesquisadores, observação direta, avaliação longitudinal

II - Casos/Fases I- Proposta de modelo

Fonte: Autoria própria (2013)

Quadro 2 - Características das firmas pesquisadas

\begin{tabular}{|c|c|c|c|}
\hline Firma & Processo e produtos & $\begin{array}{l}\mathrm{N}^{\mathrm{o}} \text { de } \\
\text { Funcio- } \\
\text { nários }\end{array}$ & $\begin{array}{l}\text { Período da } \\
\text { intervenção }\end{array}$ \\
\hline A & Fundição de utensílios de cozinha de alumínio & 67 & \multirow{6}{*}{$\begin{array}{l}\text { Maio/2009 } \\
\text { a Nov/2009 }\end{array}$} \\
\hline $\mathrm{B}$ & Fundição de alumínio e marcenaria de móveis & 45 & \\
\hline $\mathrm{C}$ & Fundição de utensílios de cozinha de alumínio & 36 & \\
\hline $\mathrm{D}$ & Fundição de utensílios de cozinha de ferro fundido & 190 & \\
\hline $\mathrm{E}$ & $\begin{array}{l}\text { Fundição de alumínio, marcenaria e caldeiraria de } \\
\text { móveis }\end{array}$ & 115 & \\
\hline $\mathrm{F}$ & Fundição de utensílios de cozinha de ferro fundido & 75 & \\
\hline
\end{tabular}

Fonte: Autoria própria (2013)

\section{Resultados e análises}

Esta seção apresenta o detalhamento dos resultados, a qual se encontra dividida em duas partes: a primeira apresenta o modelo e a proposta do processo de intervenção desenvolvido por meio da literatura e pelas experiências prévias dos pesquisadores; a segunda apresenta o contexto, o conteúdo e processo das intervenções.

\subsection{Framework de trabalho}


O framework desenvolvido está apresentado na Figura 2. As setas exemplificam a lógica do fluxo entre entradas e saídas dos métodos. Em resumo, a estratégia do SIP irá influenciar as decisões de escolha de áreas e produtos futuros no Roadmapping, na Gestão de Plataformas e na Gestão do Portfólio.

Figura 2 - Modelo conceitual de trabalho elaborado

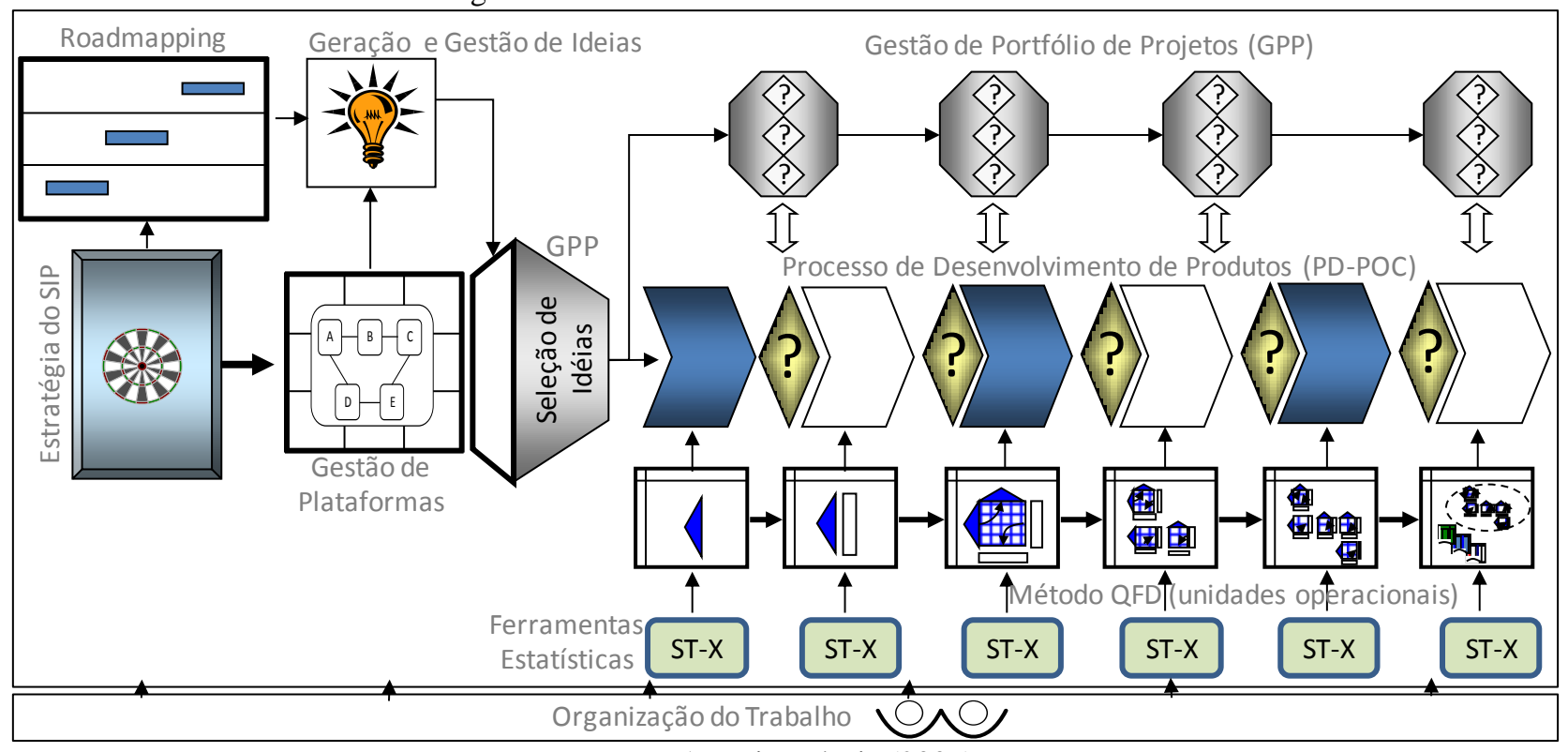

Fonte: Autoria própria (2009)

Segundo Kotter (1995), a criação da visão auxilia no direcionamento dos esforços para a mudança. Estratégias são desenvolvidas com foco na obtenção desta visão, a qual deve ser comunicada a todos envolvidos. O Roadmapping e Gestão de Plataformas auxiliam no levantamento de ideias de produtos que são geridas. As ideias podem ser comparadas com os projetos ativos e em espera, selecionadas e priorizadas na gestão de portfólio realizada periodicamente. As ideias selecionadas, bem como os projetos ativos, passam por um fluxo de desenvolvimento chamado de Processo de Desenvolvimento de Produtos Orientado ao Ciente (PDPOC). As etapas e atividades deste processo foram desenvolvidas para serem utilizados em conjunto com unidades operacionais do Método QFD (tabelas, matrizes, modelo conceitual, padrões). O formato estabelecido para este PD-POC seguiu o modelo proposto por Cooper (2008) de estágios e momentos de decisão. Por fim, seriam mensurados os resultados dos produtos no mercado, como faturamento e satisfação do cliente.

\subsection{Processo de intervenção}

Diagnóstico: contextualização e adaptação de conteúdo

Os agentes da mudança foram dois pesquisadores mestres em engenharia da produção e dois bolsistas de graduação em engenharia de produção. Realizou-se um seminário inicial de duas horas 
em que participaram de dois a três integrantes das firmas. As pessoas convidadas foram os empresários e responsáveis pelo desenvolvimento de produtos das mesmas. Nesta pesquisa, dois fatores de sucesso almejados, e consonantes com o trabalho de Done et al (2011), foram a comunicação da estratégia e objetivos, além da tentativa de induzir a prontidão organizacional para a mudança.

Cada empresário alocou sua própria equipe interna, sendo que seus membros foram divididos naqueles responsáveis pela parte estratégica e outros pela parte operacional. Por se tratar de PMEs, alguns membros fizeram parte de ambos os grupos. Os responsáveis pelo trabalho estratégico foram similares ao corpo de coordenação geral sugerido por diferentes autores (ex. YUSOF e ASPINWALL, 2000). Para os WS foi sugerida às firmas a participação do empresário ou representante da firma, do responsável pelo desenvolvimento técnico dos produtos e de uma pessoa da área comercial.

Entre este primeiro seminário e o primeiro WS realizou-se uma visita exploratória às firmas com duração de 2 horas. O protocolo de busca de informações utilizado e os resultados compilados estão apresentados no Quadro 6 anexo. Os itens deste protocolo são consonantes com os fatores básicos de um SIP apresentados por Cheng e Melo Filho (2010) e por Morgan e Liker (2003).

Após resultados das visitas iniciais, os pesquisadores decidiram reduzir o conteúdo das práticas gerencias uma vez que as firmas não faziam uso de nenhum método formal da GIP e também não utilizavam em sua rotina sistemas de gestão (exceção uma firma). Além disso, muitas possuíam restrições de recursos humanos para o projeto, uma vez que os participantes somavam ações tanto do projeto quanto das atividades de rotina. E ainda, pelo fato de que o prazo para implantação de um conjunto total de práticas seria relativamente curto.

A estratégia dos pesquisadores foi reduzir e "simplificar" de modo que os métodos pudessem contribuir para a melhoria das capacidades dinâmicas de detecção, apreensão e reconfiguração, além de favorecer o desenvolvimento de pelo menos um produto piloto demonstrativo. Outra estratégia foi representar os métodos por meio de um fluxo simples em uma dimensão vertical, a partir do qual se aludia um “caminhar" dos projetos da esquerda para direita. Isto para facilitar o entendimento dos participantes em relação à dimensão temporal dos projetos, tal como utilizado por Cooper (2008) e Ulrich e Eppinger (2012).

Segundo Tidd et al (2005), as grandes ações de um sistema de GIP são: buscar ideia, selecionar e implementar. Um método que auxilia a identificação de ideias de forma "relativamente rápida" é a gestão de plataformas (MEYER, 1997), pois permite num primeiro a identificação dos recursos internos plataformas que, quando rapidamente reconfigurados, permitem $o$ desenvolvimento de novos produtos. Assim, o método de gestão de plataformas auxiliaria a melhoria das capacidades dinâmicas de detecção e reconfiguração da firma. Para selecionar as 
ideias, decidiu-se utilizar apenas o primeiro estágio da gestão de portfólio, deixando-se de lado a gestão periódica, conforme sugere Cooper et al (1998). Além disso, este método permitiria a apreensão de oportunidades. Para auxiliar a implementação operacional dos projetos e a apreensão das oportunidades, decidiu-se utilizar o PDP. Além disso, decidiu-se utilizar unidades operacionais do método QFD para identificação e organização das necessidades dos clientes. Outro antecedente do sucesso da inovação de produtos mantido no modelo adaptado foi a gestão da organização do trabalho. Os pesquisadores também acreditaram que para aplicação dos métodos seria indicado utilizar técnicas qualitativas de análises e não ferramentas estatísticas ou análises financeiras elaboradas, pois aparentemente aquelas seriam técnicas mais avançadas. Em resumo, o objetivo foi implementar um estágio inicial da GIP para melhorar a rotina de inovação de produtos, a partir do qual iniciou-se os princípios básicos de uma gestão de desenvolvimento enxuta. O framework adaptado está apresentado na Figura 3.

Figura 3 - Modelo conceitual de trabalho simplificado e Processo de Desenvolvimento de Produtos Orientado aos Clientes (PD-POC)

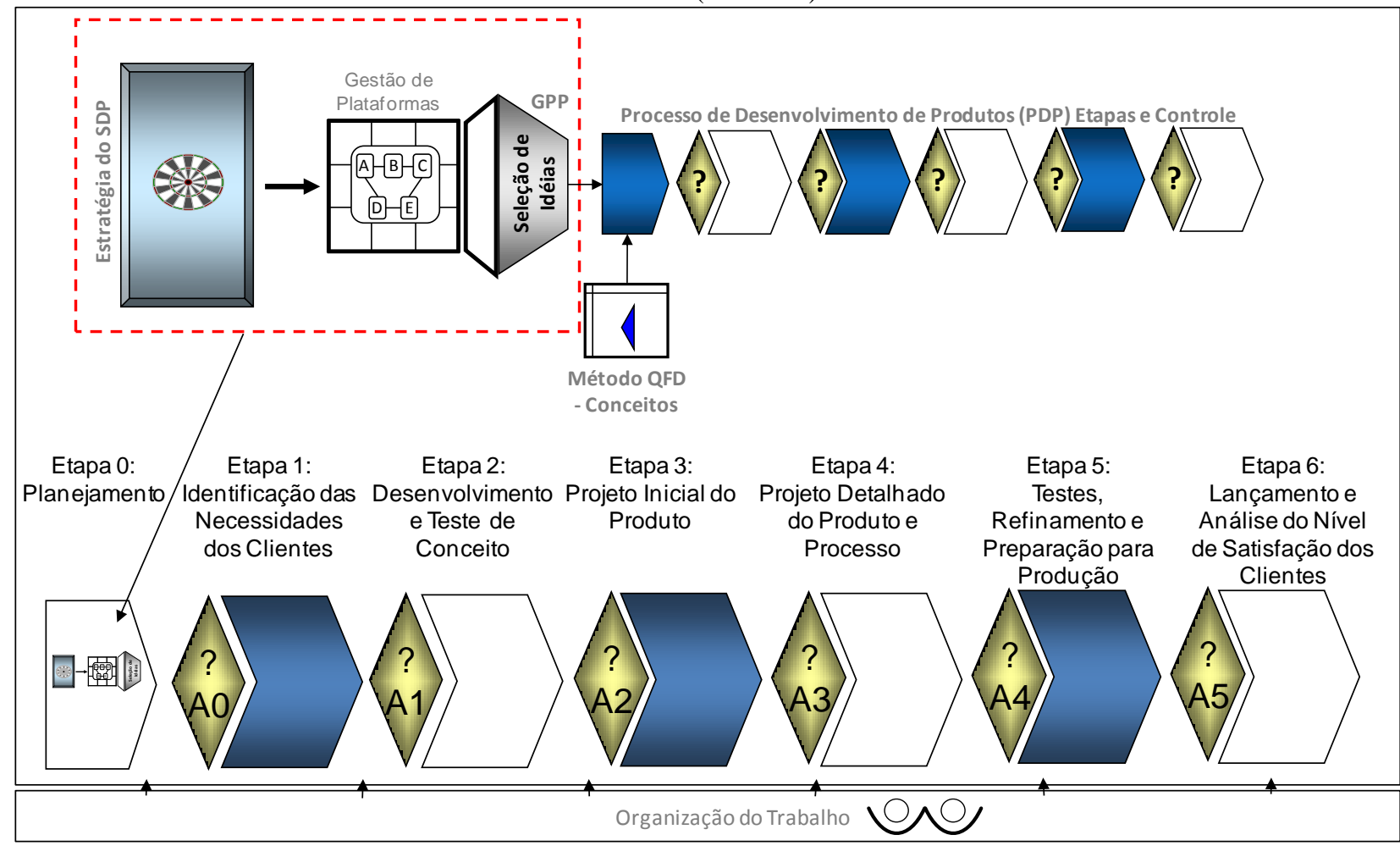

Fonte: Autoria própria (2009)

Como tentativa de simplificar o modelo, a visão estratégica do SIP, a Gestão de Plataformas e a fase inicial da Gestão de Portfólio foram simbolizadas como pertencentes à etapa de Planejamento. O fluxo de trabalho final adaptado e normatizado nas firmas foi nomeado de PDPOC com o objetivo de ser utilizado e referenciado na rotina de trabalho por meio do mimetismo, como outras "siglas de gestão" já utilizadas (ex. TQM, CCQ e 5S). Uma proposição de pesquisa 
levantada foi: o modelo conceitual de trabalho simplificado, adaptado e implantado auxiliaria as firmas na gestão da inovação de produtos.

\section{Planejamento: processo de intervenção e resultados esperados}

Seis WS periódicos foram realizados com duração de quatro horas cada (três a quatro semanas de "intervalo" entre os WS). Neles foram repassados conceitos, atividades práticas sobre o conteúdo e para-casa para as firmas. Entre os WS cada firma recebeu visitas técnicas de duas horas de duração (Figura 4). Além das atividades práticas, os pesquisadores prepararam conteúdos para WS e exercícios de para-casa, com análise periódica dos resultados. Os conteúdos trabalhados nos WS estão exemplificados no Quadro 3.
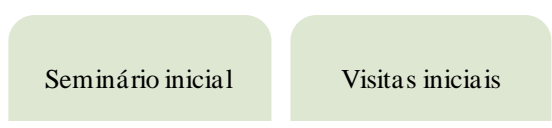

Figura 4 - Processo de intervenção
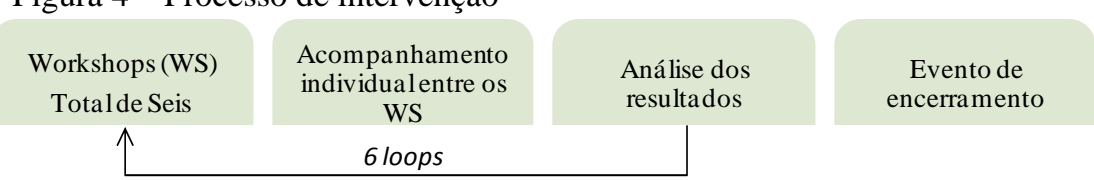

Fonte: Autoria própria (2009)

Quadro 3-Workshops e para-casas processo de intervenção

\begin{tabular}{|c|c|c|}
\hline WS & Tópico & Conteúdo \\
\hline I & $\begin{array}{l}\text { Importância da GIP; } \\
\text { Conceitos Básicos; e } \\
\text { Organização do Traballho }\end{array}$ & $\begin{array}{l}\text { Contextualização e apresentação do programa; importância da GIP; Da } \\
\text { Imitação à Inovação (KIM, 2005); caracterização da GIP; estratégias do SDP; } \\
\text { tipologia de projetos de desenvolvimento de produtos; mensuração do SDP; } \\
\text { visão geral do PD-POC; organização do trabalho }\end{array}$ \\
\hline \multicolumn{2}{|c|}{ Atividade para-casa I } & $\begin{array}{l}\text { Definição da equipe estratégica e operacional; definição da liderança } \\
\text { operacional; estabelecimento de uma declaração da estratégia do SDP; } \\
\text { estabelecimento de critérios de mensuração do sucesso do SDP. }\end{array}$ \\
\hline II & $\begin{array}{l}\text { Métodos para Gestão } \\
\text { Estratégica Parte I }\end{array}$ & - Revisão; Gestão da Plataforma de Produtos - conceitos introdutórios \\
\hline \multicolumn{2}{|c|}{ Atividade para-casa II } & $\begin{array}{l}\text { Definiçãa do nicho de mercado de atuação; definição da plataforma } \\
\text { tecnológica atual; geração de ideias de novos produtos }\end{array}$ \\
\hline III & $\begin{array}{l}\text { Métodos para Gestão } \\
\text { Estratégica Parte II e Registro } \\
\text { de Desenho Industrial }\end{array}$ & $\begin{array}{l}\text { - Revisão; registro de desenho industrial e patentes } \\
\text { - Gestão do Portfólio de Projetos de Novos Produtos - conceitos introdutórios } \\
\text { para seleção de projetos- I }\end{array}$ \\
\hline \multicolumn{2}{|c|}{ Atividade para-casa III } & $\begin{array}{l}\text { Ensaiar a seleção de produtos por meio da técnica de modelos de pontuação e } \\
\text { gráfico de bolhas (Cooper, 1997a) }\end{array}$ \\
\hline IV & $\begin{array}{l}\text { Métodos para Gestão } \\
\text { Operacional: Parte I }\end{array}$ & $\begin{array}{l}\text { - Revisão; Etapa } 1 \text { do PD-POC e o método QFD - conceitos introdutórios e a } \\
\text { tabela de qualidade exigida (TQE); gestão a vista }\end{array}$ \\
\hline \multicolumn{2}{|c|}{ Atividade para-casa IV } & $\begin{array}{l}\text { Realizar gestão a vista da Gestão de Plataforma, Gestão de Portfólio e PD- } \\
\text { POC; alocar os projetos atuais em alguma etapa do PD-POC; ensaiar a } \\
\text { construção de uma tabela de qualidade exigida (TQE) por meio de pesquisa } \\
\text { externa ou interna }\end{array}$ \\
\hline $\mathrm{V}$ & $\begin{array}{l}\text { Métodos para Gestão } \\
\text { Operacional: Parte II }\end{array}$ & - Revisão; Etapas 2 e 3 do PD-POC \\
\hline \multicolumn{2}{|c|}{ Atividade para-casa $\mathrm{V}$} & $\begin{array}{l}\text { - Ensaiar a definição de especificação técnicas em função das expectativas de } \\
\text { clientes; ensaiar o desenvolvimento de um plano de marketing de novos } \\
\text { produtos; e/ou formalizar o início do processo de desenvolvimento para firma } \\
\text { por meio do apoio e controle da alta gerência e formalização de documentos } \\
\text { padrões }\end{array}$ \\
\hline VI & $\begin{array}{l}\text { Métodos para Gestão } \\
\text { Operacional: Parte III }\end{array}$ & - Revisão; Etapas 4, 5 e 6 do PD-POC \\
\hline \multicolumn{2}{|c|}{ Atividade para-casa VI } & - Ensaiar o projeto detalhado do produto e processo, prototipagem, produção \\
\hline
\end{tabular}




\begin{tabular}{|l|l|l|}
\hline WS & \multicolumn{1}{|c|}{ Tópico } & \multicolumn{1}{c|}{ Conteúdo } \\
\hline & & $\begin{array}{l}\text { inicial e lançamento; e/ou formalizar todo o processo de desenvolvimento para } \\
\text { firma por meio do apoio e controle da alta gerência e formalização de } \\
\text { documentos padrões }\end{array}$ \\
\hline
\end{tabular}

Fonte: Autoria própria (2009)

Para realização das atividades de para-casa, desenvolveu-se planilhas eletrônicas adaptadas e utilizadas ao longo da rotina de trabalho das firmas. Estas foram entregues em um documento de exercício impresso e também em formato eletrônico. Nestas atividades forneceu-se a opção de "ensaiar" (simular), pois nem todas as firmas estariam no momento de desenvolver produtos conforme andamento dos cursos.

\section{Ação, resultados e avaliações}

Os resultados coletados estão resumidos no Quadro 4. Após 8 meses de encerramento das atividades do programa, um dos pesquisadores retornou a algumas das firmas com o objetivo de avaliar os resultados de longo prazo alcançados. Para tanto, a coleta de dados foi apoiada pelo uso da observação direta e por entrevistas não estruturada com os sócios. As exceções de coleta foram as firmas D e E, pois apresentaram problemas de agenda. O Quadro 5 exemplifica resultados alcançados pela firma $\mathrm{A}$.

Em geral, três firmas (A, B e C) obtiveram resultados satisfatórios conforme planejamento da intervenção, uma vez que melhoraram suas capacidades de gestão inovação. Duas firmas (D e F) obtiveram resultados parciais, enquanto uma firma obteve resultados insatisfatórios. As firmas em que a alta gerência não se comprometeu com o programa os resultados planejados não foram alcançados.

Durante o evento de encerramento aplicou-se um questionário estruturado para verificar a percepção dos participantes em relação aos resultados obtidos, em especial no que tange à melhoria de capacidades dinâmicas para inovação de produtos (Quadro 7 anexo).

Os resultados mostraram que houve uma melhoria das capacidades dinâmicas das firmas (TEECE, 2007) relacionadas com a gestão de inovação de produtos. Firmas estariam mais aptas a detectar e apreender oportunidades, pois melhoraram seu planejamento estratégico e processo formal de inovação de produtos. Também estariam mais aptas e reconfigurar seus recursos, pois implementaram conceitos da gestão de plataformas.

\section{Conclusões - lições aprendidas}

O seminário inicial realizado foi similar ao workshop (WS) para os diretores apresentado por Done et al (2011), cujas metas foram a comunicação da estratégia e dos objetivos da pesquisa, além da tentativa de se induzir a prontidão organizacional para a mudança. Para os mesmos 
autores, isto são fatores de sucesso. Duas firmas em que a alta gerência não se comprometeu com o programa os resultados planejados não foram alcançados. Durante visitas iniciais realizadas após este seminário verificou-se que as firmas não faziam uso de nenhum método formal da Gestão de Inovação de Produtos (GIP). A exceção foi o uso de ferramentas de CAD, mesmo resultado encontrado por Kaminski et al (2008).

Quadro 4 - Protocolo de identificação de resultados gerais

\begin{tabular}{|c|c|c|c|c|c|c|}
\hline \multirow{2}{*}{ Itens } & \multicolumn{6}{|c|}{ Firmas } \\
\hline & $\mathbf{A}$ & B & $\mathrm{C}$ & D & $\mathbf{E}$ & $\mathbf{F}$ \\
\hline $\begin{array}{l}\text { Resultado de } \\
\text { curto prazo } \\
\text { Capacidade de } \\
\text { detecção }\end{array}$ & $\begin{array}{l}\text { Por meio da } \\
\text { gestão de } \\
\text { plataformas foi } \\
\text { possível } \\
\text { identificar } \\
\text { novas } \\
\text { oportunidades }\end{array}$ & $\begin{array}{l}\text { Por meio da } \\
\text { gestão de } \\
\text { plataformas foi } \\
\text { possível } \\
\text { identificar } \\
\text { novas } \\
\text { oportunidades }\end{array}$ & $\begin{array}{l}\text { Por meio da } \\
\text { gestão de } \\
\text { plataformas foi } \\
\text { possível } \\
\text { identificar } \\
\text { novas } \\
\text { oportunidades }\end{array}$ & $\begin{array}{l}\text { Por meio da } \\
\text { gestão de } \\
\text { plataformas } \\
\text { foi possível } \\
\text { identificar } \\
\text { novas } \\
\text { oportunidades }\end{array}$ & $\begin{array}{c}\text { Não } \\
\text { aplicou }\end{array}$ & $\begin{array}{l}\text { Por meio da } \\
\text { gestão de } \\
\text { plataformas } \\
\text { foi possível } \\
\text { identificar } \\
\text { novas } \\
\text { oportunidades }\end{array}$ \\
\hline $\begin{array}{l}\text { Resultado de } \\
\text { curto prazo } \\
\text { Capacidade de } \\
\text { apreensão }\end{array}$ & $\begin{array}{l}\text { Por meio da } \\
\text { Gestão de } \\
\text { Portfólio } \\
\text { priorizou } \\
\text { projetos e } \\
\text { utilizou-se o } \\
\text { PD-POC e a } \\
\text { TQE no } \\
\text { desenvolvimen } \\
\text { to de produto } \\
\text { real }\end{array}$ & $\begin{array}{c}\text { Por meio da } \\
\text { Gestão de } \\
\text { Portfólio } \\
\text { priorizou } \\
\text { projetos e } \\
\text { utilizou-se o } \\
\text { PD-POC e a } \\
\text { TQE no } \\
\text { desenvolvimen } \\
\text { to de produto } \\
\text { real }\end{array}$ & $\begin{array}{l}\text { Por meio da } \\
\text { Gestão de } \\
\text { Portfólio } \\
\text { priorizou } \\
\text { projetos e } \\
\text { utilizou-se o } \\
\text { PD-POC no } \\
\text { desenvolviment } \\
\text { o de produto } \\
\text { real }\end{array}$ & $\begin{array}{l}\text { Por meio da } \\
\text { Gestão de } \\
\text { Portfólio } \\
\text { priorizaram-se } \\
\text { projetos e } \\
\text { simulou-se o } \\
\text { uso do PD- } \\
\text { POC e TQE }\end{array}$ & $\begin{array}{c}\text { Não } \\
\text { aplicou }\end{array}$ & $\begin{array}{l}\text { Por meio da } \\
\text { Gestão de } \\
\text { Portfólio } \\
\text { priorizaram-se } \\
\text { projetos e } \\
\text { simulou-se o } \\
\text { uso do PD- } \\
\text { POC }\end{array}$ \\
\hline $\begin{array}{l}\text { Resultado de } \\
\text { curto prazo } \\
\text { Capacidade de } \\
\text { reconfiguração }\end{array}$ & $\begin{array}{l}\text { Por meio da } \\
\text { gestão de } \\
\text { plataformas } \\
\text { foram } \\
\text { reconfiguradas } \\
\text { tecnologias } \\
\text { internas e } \\
\text { foram lançados } \\
\text { novos produtos }\end{array}$ & $\begin{array}{l}\text { Por meio da } \\
\text { gestão de } \\
\text { plataformas } \\
\text { foram } \\
\text { reconfiguradas } \\
\text { tecnologias } \\
\text { internas e } \\
\text { foram lançados } \\
\text { novos produtos }\end{array}$ & $\begin{array}{l}\text { Por meio da } \\
\text { gestão de } \\
\text { plataformas } \\
\text { foram } \\
\text { reconfiguradas } \\
\text { tecnologias } \\
\text { internas e foram } \\
\text { lançados novos } \\
\text { produtos }\end{array}$ & $\begin{array}{l}\text { Simulou-se a } \\
\text { reconfiguraçã } \\
\text { o de } \\
\text { tecnologias } \\
\text { para o } \\
\text { desenvolvime } \\
\text { nto de novos } \\
\text { produtos }\end{array}$ & $\begin{array}{c}\text { Não } \\
\text { aplicou }\end{array}$ & $\begin{array}{c}\text { Simulou-se a } \\
\text { reconfiguraçã } \\
\text { o de } \\
\text { tecnologias } \\
\text { para o } \\
\text { desenvolvime } \\
\text { nto de novos } \\
\text { produtos }\end{array}$ \\
\hline $\begin{array}{c}\text { Fatores } \\
\text { positivos } \\
\text { levantados ao } \\
\text { longo do } \\
\text { processo de } \\
\text { intervenção }\end{array}$ & $\begin{array}{l}\text { Apoio da alta } \\
\text { gerência; } \\
\text { participação do } \\
\text { empresário e } \\
\text { técnico } \\
\text { responsável } \\
\text { pelo } \\
\text { desenvolvimen } \\
\text { to em todos os } \\
\text { WS. Houve } \\
\text { comprometime } \\
\text { nto e prontidão } \\
\text { para mudança }\end{array}$ & $\begin{array}{l}\text { Apoio da alta } \\
\text { gerência; } \\
\text { participação do } \\
\text { empresário e } \\
\text { técnico } \\
\text { responsável } \\
\text { pelo } \\
\text { desenvolvimen } \\
\text { to em todos os } \\
\text { WS. Houve } \\
\text { comprometime } \\
\text { nto e prontidão } \\
\text { para mudança }\end{array}$ & $\begin{array}{l}\text { Participaram de } \\
\text { todos WS e se } \\
\text { dedicaram da } \\
\text { realização dos } \\
\text { para-casas }\end{array}$ & $\begin{array}{l}\text { A gestora } \\
\text { responsável } \\
\text { pela qualidade } \\
\text { participou de } \\
\text { todos WS }\end{array}$ & $\begin{array}{l}\text { Participara } \\
\text { m de } \\
\text { alguns WS }\end{array}$ & $\begin{array}{c}\text { Relativo apoio } \\
\text { da alta } \\
\text { gerência }\end{array}$ \\
\hline
\end{tabular}




\begin{tabular}{|c|c|c|c|c|c|c|}
\hline \multirow{2}{*}{ Itens } & \multicolumn{6}{|c|}{ Firmas } \\
\hline & $\mathbf{A}$ & B & $\mathbf{C}$ & D & $\mathbf{E}$ & $\mathbf{F}$ \\
\hline $\begin{array}{c}\text { Fatores } \\
\text { negativos } \\
\text { levantados ao } \\
\text { longo do } \\
\text { processo de } \\
\text { intervenção }\end{array}$ & $\begin{array}{l}\text { Dificuldade de } \\
\text { alocação de } \\
\text { recursos } \\
\text { humanos para } \\
\text { realização das } \\
\text { atividades de } \\
\text { para-casa }\end{array}$ & $\begin{array}{l}\text { Dificuldade de } \\
\text { alocação de } \\
\text { recursos } \\
\text { humanos para } \\
\text { realização das } \\
\text { atividades de } \\
\text { para-casa }\end{array}$ & $\begin{array}{c}\text { Não houve } \\
\text { apoio integral } \\
\text { da alta gerencia } \\
\text { (mostraram } \\
\text { comprometime } \\
\text { nto, mas na } \\
\text { prática } \\
\text { restringiu } \\
\text { recursos). O } \\
\text { empresário não } \\
\text { participou dos } \\
\text { WS. } \\
\end{array}$ & $\begin{array}{c}\text { Não houve } \\
\text { apoio integral } \\
\text { da alta } \\
\text { gerencia. A } \\
\text { gestora não } \\
\text { realizou } \\
\text { atividades de } \\
\text { para-casa }\end{array}$ & $\begin{array}{l}\text { Não houve } \\
\text { apoio da } \\
\text { alta } \\
\text { gerência. } \\
\text { Os } \\
\text { empresári } \\
\text { os não } \\
\text { queriam } \\
\text { mudanças } \\
\text { no } \\
\text { momento }\end{array}$ & $\begin{array}{c}\text { Não } \\
\text { participaram } \\
\text { de todos WS e } \\
\text { não } \\
\text { realizaram } \\
\text { todos para- } \\
\text { casas }\end{array}$ \\
\hline $\begin{array}{c}\text { Resultados de } \\
\text { médio/longo } \\
\text { prazo } \\
\text { Capacidades } \\
\text { dinâmicas } \\
\text { (entrevistas/visi } \\
\text { tas técnicas } \\
\text { realizada após } \\
8 \text { meses de } \\
\text { encerramento } \\
\text { das atividades) }\end{array}$ & $\begin{array}{c}\text { Após } 8 \text { meses } \\
\text { do termino, } \\
\text { manteve-se o } \\
\text { uso da Gestão } \\
\text { de Plataformas, } \\
\text { Gestão de } \\
\text { Portfólio, PD- } \\
\text { POC em gestão } \\
\text { a vista e TQE, } \\
\text { e elevou-se o } \\
\text { faturamento } \\
\text { por meio do } \\
\text { lançamento de } \\
\text { novos produtos }\end{array}$ & $\begin{array}{c}\text { Após } 8 \text { meses } \\
\text { do termino, } \\
\text { manteve-se o } \\
\text { uso da Gestão } \\
\text { de Plataformas, } \\
\text { Gestão de } \\
\text { Portfólio e PD- } \\
\text { POC em gestão } \\
\text { a vista. A firma } \\
\text { alterou etapas e } \\
\text { atividades do } \\
\text { PD-POC e } \\
\text { elevou o } \\
\text { faturamento } \\
\text { por meio do } \\
\text { lançamento de } \\
\text { novos produtos }\end{array}$ & $\begin{array}{l}\text { Após } 8 \text { meses } \\
\text { do termino, } \\
\text { manteve-se o } \\
\text { uso de } \\
\text { princípios da } \\
\text { Gestão de } \\
\text { Plataformas, } \\
\text { Gestão de } \\
\text { Portfólio e PD- } \\
\text { POC. Mas não } \\
\text { formalizado. } \\
\text { Elevou o } \\
\text { faturamento por } \\
\text { meio do } \\
\text { lançamento de } \\
\text { novos produtos }\end{array}$ & $\begin{array}{c}\text { Não } \\
\text { verificado }\end{array}$ & $\begin{array}{c}\text { Não } \\
\text { verificado }\end{array}$ & $\begin{array}{l}\text { Aparentement } \\
\text { e não } \\
\text { alcançado, } \\
\text { apenas } \\
\text { "elevação" do } \\
\text { conhecimento } \\
\text { dos } \\
\text { participantes }\end{array}$ \\
\hline
\end{tabular}

Fonte: Pesquisa de campo (2010)

Quadro 5 - Exemplificação de resultados obtidos pela firma A, ao longo do processo de intervenção 1- Visão estratégica: Em 6 anos, ser reconhecida como pioneira no lançamento de utensílios domésticos de alumínio fundido no mercado centro-oeste mineiro e analisadora no mercado nacional

2 - Organização do trabalho

Conselho de Estratégia
\begin{tabular}{|c|c|}
\hline Osv & Diretor \\
\hline Graz & Gerente Administrativo \\
\hline Ale & Líder da Expedição \\
\hline Eld & Gerente de Produção \\
\hline
\end{tabular}

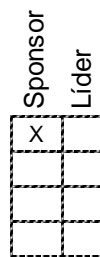

Equipe Operacional

\begin{tabular}{|c|c|}
\hline Pab & Líder da Moldação \\
\hline João & Forneiro \\
\hline José & Líder do Polimento \\
\hline Edn & Polidor \\
\hline Ren & Líder Manutenção \\
\hline Eld & Gerente de Produção \\
\hline Jaim & Inspetor de qualidade. \\
\hline
\end{tabular}

3 - Gestão de Plataformas - Definição de ideias de projetos em função dos recursos internos atuais

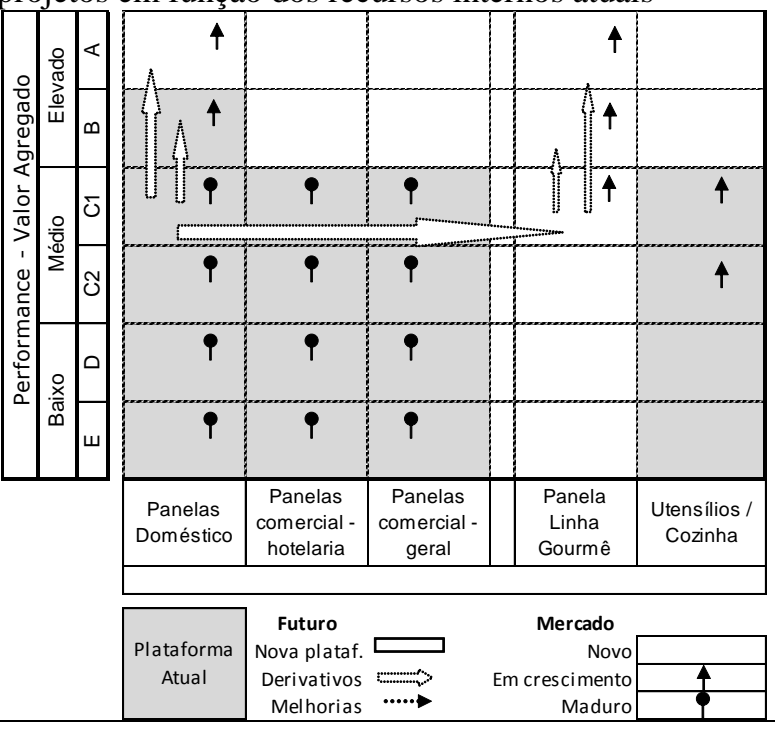




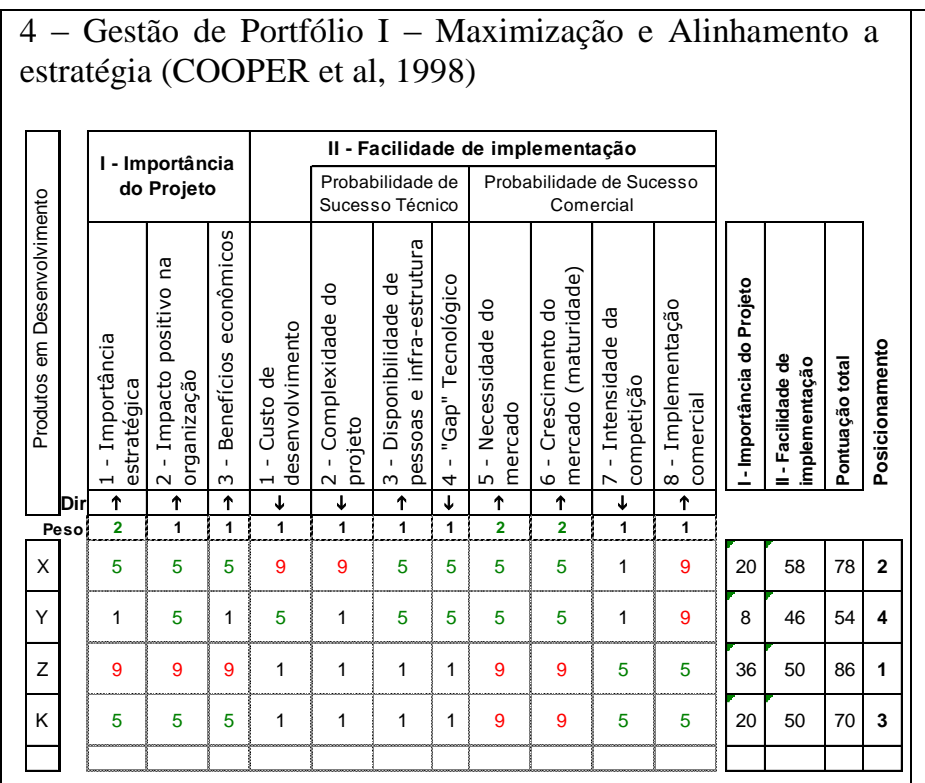

5 - Gestão de Portfólio II - Balanceamento (COOPER et al, 1998)
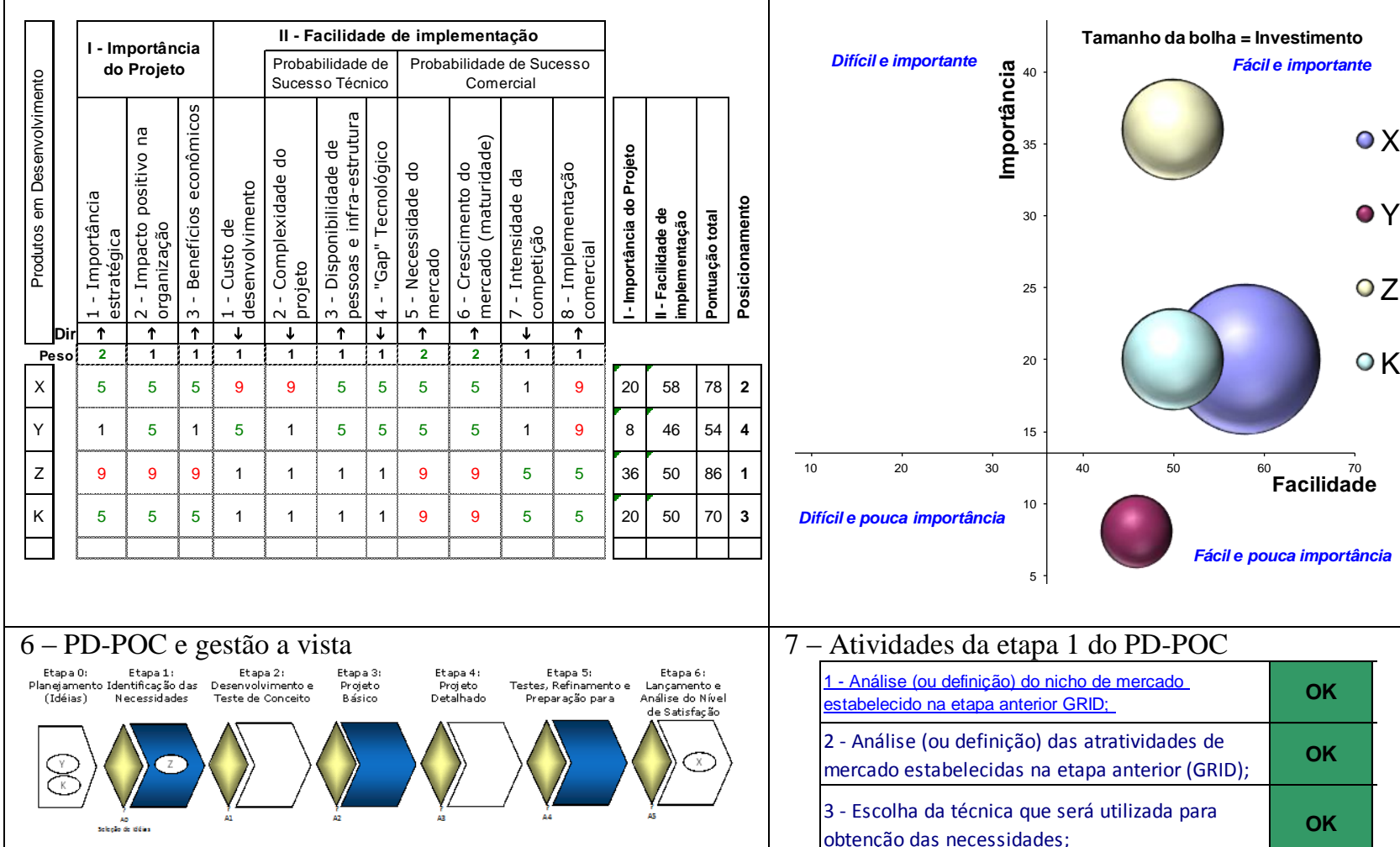

7 - Atividades da etapa 1 do PD-POC

\begin{tabular}{|c|c|}
\hline $\begin{array}{l}1 \text { - Análise (ou definicão) do nicho de mercado } \\
\text { estabelecido na etapa anterior GRID: }\end{array}$ & OK \\
\hline $\begin{array}{l}\text { 2- Análise (ou definincão) das atratividades de } \\
\text { mercado estabelecidas na etapa anterior (GRID); }\end{array}$ & OK \\
\hline $\begin{array}{l}3 \text { - Escolha da técnica que será utilizada para } \\
\text { obtenção das necessidades; }\end{array}$ & OK \\
\hline 4 - Definição dos consumidores (grupo); & OK \\
\hline 5- Obtencão da Voz dos Clientes: & OK \\
\hline $\begin{array}{l}\text { 6- Traduzir a voz do cliente em reais necessidades } \\
\text { Qualidade Exigida): }\end{array}$ & OK \\
\hline 7- Organizar as necessidades em hierarquia (Tabela). & OK \\
\hline $\begin{array}{l}\text { 8- ldentificar necessidades dos clientes intermos } \\
\text { gualidade e produtividade }\end{array}$ & OK \\
\hline 9- Revisar nicho de mercado foco & OK \\
\hline
\end{tabular}

continuação

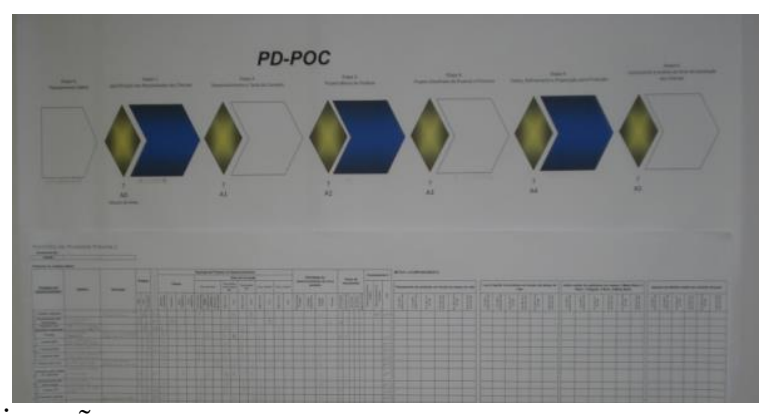

8 - TQE do projeto Z: Caçarola de alumínio fundido com antiaderente e tampa de vidro

\begin{tabular}{|c|c|c|}
\hline Nível 1 & Nível 2 & Nível 3 \\
\hline \multirow{8}{*}{ Boa aparência } & \multirow{3}{*}{$\begin{array}{c}\text { Bom } \\
\text { acabamento }\end{array}$} & Fundo bem trabalhado \\
\hline & & Fundo bonito \\
\hline & & Bom brilho \\
\hline & \multicolumn{2}{|r|}{ Alça bonita } \\
\hline & \multirow{2}{*}{ Tampa bonita } & Tampa bonita \\
\hline & & Pegador bonito \\
\hline & \multirow{2}{*}{ Bom Design } & Desenho atrativo \\
\hline & & Cores diversificadas \\
\hline \multirow{2}{*}{ Boa mobilidade } & \multicolumn{2}{|r|}{ Fácil de segurar } \\
\hline & \multicolumn{2}{|r|}{ Fácil de transportar } \\
\hline \multirow{8}{*}{ Eficiência no uso } & \multirow{3}{*}{$\begin{array}{c}\text { Condução de } \\
\text { calor } \\
\text { adequada }\end{array}$} & Esquentar o alimento homogeneamente \\
\hline & & Espessura adequada \\
\hline & & Alça resistente ao calor \\
\hline & \multirow{5}{*}{$\begin{array}{l}\text { Boa funcio- } \\
\text { nalidade }\end{array}$} & Bom encaixe Tampa-Caçarola \\
\hline & & Permitir saída de vapor/ar \\
\hline & & Permitir utilização em diferentes tamanhos de queimadores \\
\hline & & Permitir utilização em diferentes tipos de queimadores \\
\hline & & Permitir visualização da comida \\
\hline \multirow{2}{*}{ Fácil de lavar } & \multicolumn{2}{|r|}{ Alça fácil de lavar } \\
\hline & \multicolumn{2}{|r|}{ Soltar facilmente a comida } \\
\hline Permitir alimentação saudável & \multicolumn{2}{|r|}{ Pouco óleo ao cozinhar } \\
\hline \multirow{3}{*}{ Boa durabilidade } & \multicolumn{2}{|r|}{ Anti-aderente durável } \\
\hline & \multicolumn{2}{|r|}{ Alumínio resistente } \\
\hline & \multicolumn{2}{|r|}{ Boa durabilidade da alça } \\
\hline & & il de guardar \\
\hline
\end{tabular}

Desenvolvido ao longo do projeto de intervenção 1 - projeto $X$

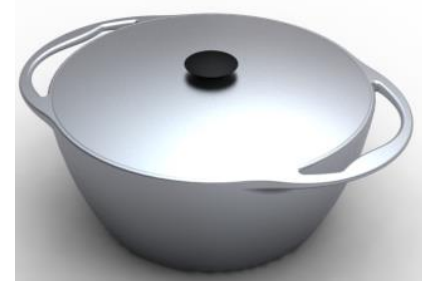

Desenvolvido após 8 meses do término do projeto de intervenção 1 com o uso dos métodos implementados - projeto $\mathrm{Z}$

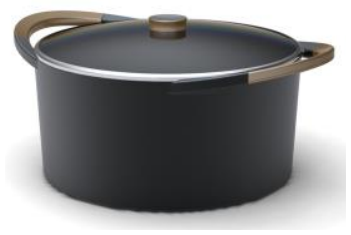

Fonte: Pesquisa de campo (2010) 
A princípio, a adaptação dos workshops e do framework à realidade das firmas contribuiu para obtenção de resultados positivos, o que está de acordo com o esperado, pois PMEs geralmente precisam modificar e adaptar as práticas adotadas pelas grandes firmas quando implementadas nelas mesmas (YUSOF e ASPINWALL, 2000). Segundo Done et al (2011), a adaptação do processo e conteúdo da intervenção ao contexto específico são fatores de sucesso de programas de intervenção.

Para Done et al (2011), a elaboração de um plano para suporte do agente às atividades em curso é um fator que influencia o sucesso no curto e longo prazo das intervenções. Nesse sentido, o processo realizado intercalou um auxílio dos agentes às firmas entre todos os workshops. Logo ressalta-se que o projeto utilizou a abordagem sugerida por Done et al (2011) não após o programa, mas ao longo do mesmo.

A pesquisa longitudinal mostrou que, ao longo do programa de intervenção, três firmas desenvolveram um produto piloto com o uso dos métodos implantados. Além disso, continuaram com o uso destas práticas, inclusive com atualizações e adaptações, após oito meses do final das atividades. Este fato reforça a tese de que processos gerenciais relacionados com a inovação são capacidades dinâmicas, pois, segundo Zollo e Winter (2002), as rotinas não são estáticas, mas sim um processo de padronização e modificação constantes. Estes resultados são consonantes com a afirmação de Done et al (2011) de que resultados de curto prazo são importantes para favorecimento da manutenção das práticas voltadas para obtenção de resultados de médio/longo prazo.

O conteúdo e processo de estratégia (WIT e MEYER, 2010) permitiram o alcance de desempenho satisfatório para o contexto trabalhado. O modelo conceitual de trabalho (framework), composto por métodos configurados, processo de intervenção e ferramentas elaboradas e adaptadas, permitiu que as PMEs implementassem uma rotina inicial de gestão de desenvolvimento de produtos, sendo que em que alguns casos possibilitou resultados positivos de curto e médio/longo prazo. Este processo utilizou etapas similares às levantadas na literatura (ex. YUSOF e ASPINWALL, 2000; DONE et al, 2011), embora a novidade esteja no número de workshops realizados e nos conteúdos das práticas gerenciais.

A perspectiva estratégia de trabalhar primeiro os recursos internos das firmas, conforme teoria da VBR (BARNEY, 1991), em especial a melhoria de suas capacidades dinâmicas (TEECE, 2007) de inovação, mostrou ser adequada para o contexto pesquisado. No entanto, não se avaliou objetivamente, na perspectiva dos participantes, o quanto o processo de intervenção e as competências dos agentes da mudança (DONE et al, 2011) impactaram os resultados positivos e negativos.

Um fator considerado positivo ao longo da intervenção foi a formulação de estratégias específicas para cada firma, o diálogo entre agentes e participantes, o diálogo induzido entre os 
participantes e a utilização de dados reais das firmas ao longo das atividades. Segundo Assarlind et al (2013), este são fatores que impactam positivamente os resultados de intervenções.

O processo observado possuiu características tanto de mudanças planejadas e emergentes (BURNES, 1996; BY, 2005), quanto de mudanças segundo a Teoria E e O (BEER; NOHRIA, 2000). Apesar do processo ter sido planejado em um programa definido a priori, e ainda ter sido conduzido de cima para baixo hierarquicamente, ocorreram conscientizações e adaptações dos métodos as contingências das firmas ao longo do tempo, como observado na firma B. Além disso, houve o objetivo de obtenção de mudança de capacidades organizacionais, o que incorreu num processo baseado no envolvimento e experimentação, como sugere a Teoria $\mathrm{O}$.

Para pesquisas futuras é sugerido a adaptação, implementação e avaliação do framework e processo de intervenção aqui desenvolvidos em outros programas de mesmo cunho, porém que sejam desenvolvidos em diferentes setores industriais. 


\section{0 - Anexos}

Quadro 6 - Protocolo de obtenção de dados das firmas durante primeiras visitas pré-intervenção

\begin{tabular}{|c|c|c|c|c|c|c|}
\hline Itens & $\mathrm{A}$ & B & $\mathrm{C}$ & $\mathrm{D}$ & $\mathrm{E}$ & $\mathrm{F}$ \\
\hline $\begin{array}{c}\text { Planejamento } \\
\text { Estratégico de } \\
\text { Desenvolvimento } \\
\text { de Novos } \\
\text { Produtos (DNP) }\end{array}$ & $\begin{array}{l}\text { Empírico } \\
\text { baseado nas } \\
\text { ideias do } \\
\text { empresário e } \\
\text { técnico }\end{array}$ & $\begin{array}{c}\text { Empírico } \\
\text { baseado nas } \\
\text { ideias do } \\
\text { empresário e } \\
\text { técnico }\end{array}$ & $\begin{array}{c}\text { Empírico } \\
\text { baseado nas } \\
\text { ideias do } \\
\text { empresário e } \\
\text { técnico }\end{array}$ & $\begin{array}{c}\text { Contratação } \\
\text { rotineira de } \\
\text { serviços de } \\
\text { design } \\
\text { externo }\end{array}$ & $\begin{array}{l}\text { Contratação } \\
\text { rotineira de } \\
\text { serviços de } \\
\text { design } \\
\text { externo }\end{array}$ & $\begin{array}{c}\text { Empírico } \\
\text { baseado nas } \\
\text { ideias do } \\
\text { empresário e } \\
\text { técnico }\end{array}$ \\
\hline $\begin{array}{l}\text { Estratégia do } \\
\text { DNP }\end{array}$ & $\begin{array}{l}\text { Principalmente } \\
\text { cópia legal e } \\
\text { um pouco de } \\
\text { imitação } \\
\text { criativa de } \\
\text { design externo } \\
\text { (forma) }\end{array}$ & $\begin{array}{l}\text { Principalmente } \\
\text { cópia legal e } \\
\text { um pouco de } \\
\text { imitação } \\
\text { criativa de } \\
\text { design externo }\end{array}$ & $\begin{array}{l}\text { Principalmente } \\
\text { cópia legal e } \\
\text { um pouco de } \\
\text { imitação } \\
\text { criativa de } \\
\text { design externo }\end{array}$ & $\begin{array}{l}\text { Cópia legal } \\
\text { e imitação } \\
\text { criativa de } \\
\text { design } \\
\text { externo }\end{array}$ & $\begin{array}{l}\text { Cópia legal e } \\
\text { imitação } \\
\text { criativa de } \\
\text { design } \\
\text { externo }\end{array}$ & $\begin{array}{l}\text { Principalmente } \\
\text { cópia legal e } \\
\text { um pouco de } \\
\text { imitação } \\
\text { criativa de } \\
\text { design externo }\end{array}$ \\
\hline $\begin{array}{c}\text { Processo Formal } \\
\text { de DNP }\end{array}$ & Não & Não & Não & Não & Não & Não \\
\hline $\begin{array}{l}\text { Mensuração do } \\
\text { SDP }\end{array}$ & Não & Não & Não & Não & Não & Não \\
\hline $\begin{array}{c}\text { Faz uso de } \\
\text { Métodos e } \\
\text { Técnicas no DNP }\end{array}$ & Apenas CAD & Apenas CAD & Apenas CAD & $\begin{array}{l}\text { Apenas } \\
\text { CAD }\end{array}$ & Apenas CAD & Apenas CAD \\
\hline $\begin{array}{c}\text { Existe uma } \\
\text { organização do } \\
\text { trabalho formal } \\
\text { para o DNP }\end{array}$ & Não & Não & Não & Não & Não & Não \\
\hline $\begin{array}{c}\text { Recursos para o } \\
\text { DNP }\end{array}$ & $\begin{array}{l}\text { Materiais para } \\
\text { construção de } \\
\text { modelo e } \\
\text { protótipo }\end{array}$ & $\begin{array}{l}\text { Materiais para } \\
\text { construção de } \\
\text { modelo e } \\
\text { protótipo }\end{array}$ & $\begin{array}{l}\text { Materiais para } \\
\text { construção de } \\
\text { modelo e } \\
\text { protótipo }\end{array}$ & $\begin{array}{c}\text { Materiais } \\
\text { para } \\
\text { construção } \\
\text { de modelo } \\
\text { e protótipo }\end{array}$ & $\begin{array}{c}\text { Materiais } \\
\text { para } \\
\text { construção de } \\
\text { modelo e } \\
\text { protótipo }\end{array}$ & $\begin{array}{l}\text { Materiais para } \\
\text { construção de } \\
\text { modelo e } \\
\text { protótipo }\end{array}$ \\
\hline $\begin{array}{l}\text { Qualificação } \\
\text { profissional }\end{array}$ & $\begin{array}{l}\text { Ensino básico } \\
\text { e médio; } \\
\text { gestora } \\
\text { financeira com } \\
\text { curso superior }\end{array}$ & $\begin{array}{l}\text { Ensino básico } \\
\text { e médio }\end{array}$ & $\begin{array}{l}\text { Ensino básico } \\
\text { e médio }\end{array}$ & $\begin{array}{l}\text { Ensino } \\
\text { básico e } \\
\text { médio; } \\
\text { donos e } \\
\text { gestor da } \\
\text { produção } \\
\text { com curso } \\
\text { superior }\end{array}$ & $\begin{array}{c}\text { Ensino } \\
\text { básico e } \\
\text { médio; } \\
\text { donos, } \\
\text { gestor da } \\
\text { produção e } \\
\text { administrador } \\
\text { financeiro } \\
\text { com curso } \\
\text { superior }\end{array}$ & $\begin{array}{l}\text { Ensino básico } \\
\text { e médio com } \\
\text { donos e gestor } \\
\text { da qualidade } \\
\text { com curso } \\
\text { superior }\end{array}$ \\
\hline $\begin{array}{c}\text { Sistemas de } \\
\text { gestão utilizados }\end{array}$ & $\begin{array}{l}\text { Nenhum } \\
\text { certificado (ex. } \\
\text { ISO 9000). } \\
\text { Uso de } \\
\text { princípios do } \\
\text { TQM, como } \\
\text { controle do } \\
\text { processo de } \\
\text { produção }\end{array}$ & $\begin{array}{l}\text { Nenhum } \\
\text { certificado (ex. } \\
\text { ISO 9000). } \\
\text { Uso de } \\
\text { princípios do } \\
\text { TQM, como } \\
\text { controle do } \\
\text { processo de } \\
\text { produção }\end{array}$ & $\begin{array}{c}\text { Nenhum } \\
\text { certificado (ex. } \\
\text { ISO 9000). } \\
\text { Uso de } \\
\text { princípios do } \\
\text { TQM, como } \\
\text { controle do } \\
\text { processo de } \\
\text { produção }\end{array}$ & $\begin{array}{c}\text { Certificada } \\
\text { na ISO } \\
9000 . \text { Uso } \\
\text { de } \\
\text { princípios } \\
\text { do TQM }\end{array}$ & $\begin{array}{c}\text { Nenhum } \\
\text { certificado } \\
\text { (ex. ISO } \\
\text { 9000). Uso } \\
\text { de princípios } \\
\text { do TQM, } \\
\text { como } \\
\text { controle do } \\
\text { processo de } \\
\text { produção }\end{array}$ & $\begin{array}{c}\text { Nenhum } \\
\text { certificado (ex. } \\
\text { ISO 9000). } \\
\text { Uso de } \\
\text { princípios do } \\
\text { TQM, como } \\
\text { controle do } \\
\text { processo de } \\
\text { produção }\end{array}$ \\
\hline
\end{tabular}

Fonte: Pesquisa de campo 2009 
Quadro 7 - Resultados do questionário final de avaliação dos resultados da intervenção

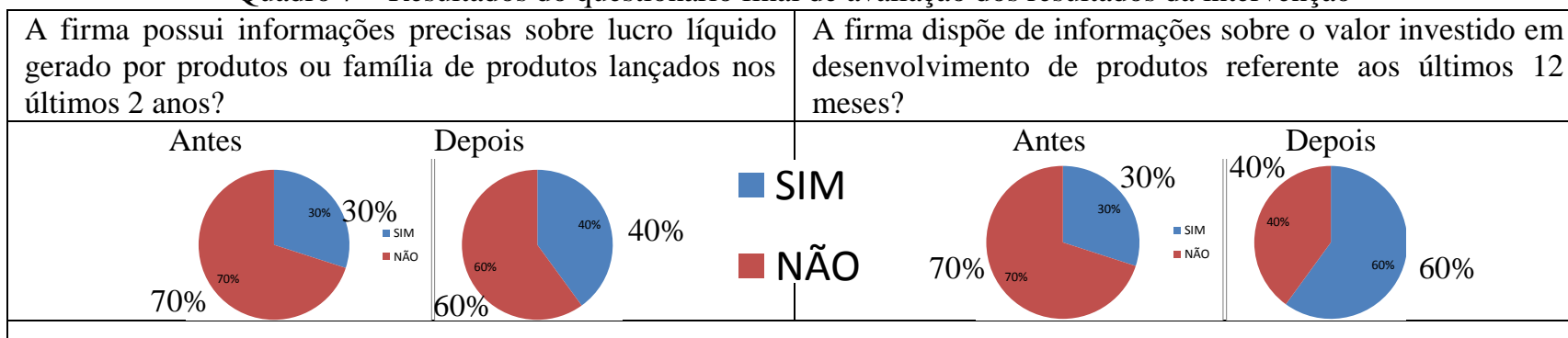

\begin{tabular}{|c|c|}
\hline $\begin{array}{l}\text { Possuem informações sobre o grau de satisfação do cliente } \\
\text { com produtos lançados nos últimos } 12 \text { meses? }\end{array}$ & $\begin{array}{l}\text { Possuem informações sobre a quantidade de defeitos } \\
\text { gerados para produtos lançados nos últimos } 12 \text { meses? }\end{array}$ \\
\hline 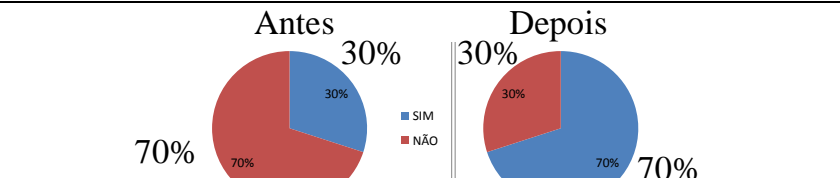 & $\underbrace{}_{50 \%}$ Antes $50 \%$ \\
\hline
\end{tabular}

Em geral, a firma possui um instrumento formal para mensuração do SDP?

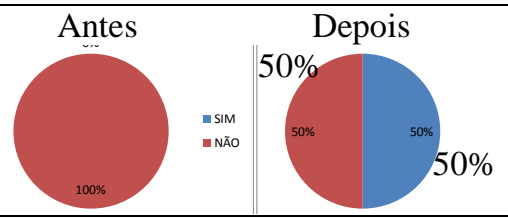

Possui uma caracterização da visão estratégia de Possui um planejamento estratégico de desenvolvimento desenvolvimento de produtos? de novos produtos (DNP)?

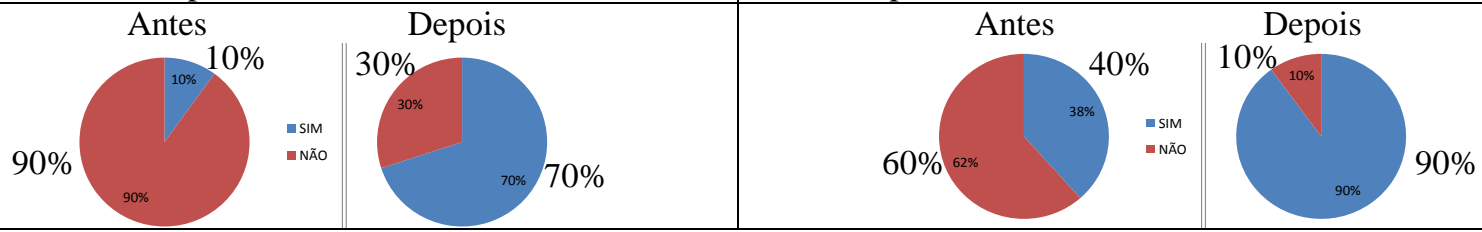

A firma trabalha com o conceito de plataforma para $\quad$ A firma possui um processo formal de DNP? adaptar tecnologias atuais e lançar novos produtos?
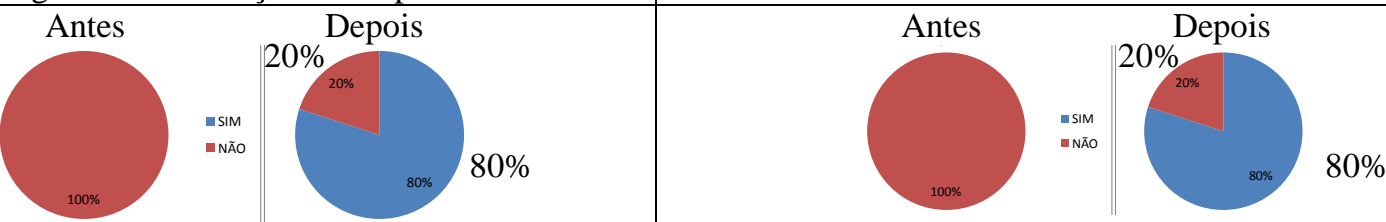

A firma faz uso de Métodos e Técnicas ao longo do $\quad$ Existe uma organização do trabalho formal para o DNP? desenvolvimento operacional do produto?

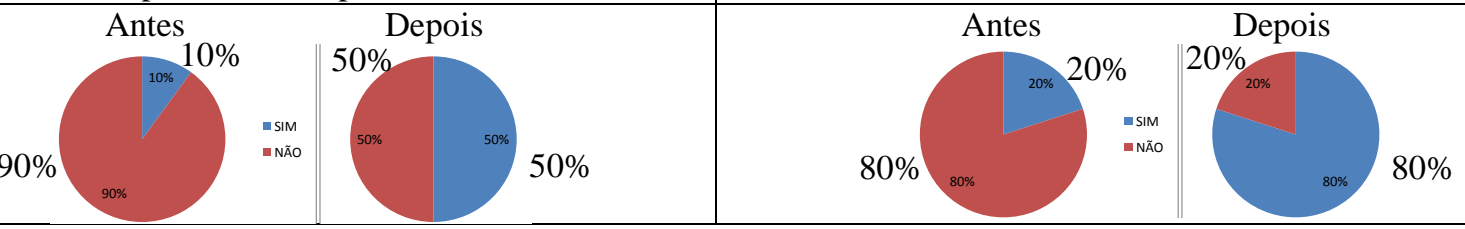

Afirma possui uma infraestrutura adequada para o DNP?

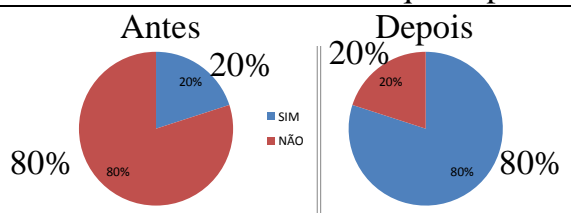

Fonte: Pesquisa de campo 2009 


\begin{abstract}
This paper aims to present an application of a framework and its intervention procedure concerning a study that sought to evaluate management practices for product innovation, focusing on those configured as Dynamic Capabilities (DC). The interventions' strategy formulation and implementation were based on the perspective of the Resource-Based View and Dynamic Capabilities, by using the study and application of configured methods. Six foundry firms of the $M G$ 's west central region were studied during the same intervention program which aimed to introduce management practices. The methodological approach used was action research, with which was associated the application of different methods of data collection (e.g. search protocol and storage of information, documentation and analysis of structured interview). The results showed that the program contributed to the implementation of management practices in product innovation, which were adapted according to the organizational contingencies related to CDs sensing, seizing, and technological reconfiguration. During the program, considering the use of the new practices, some SMEs were able to develop and launch new products with greater success, while others showed improvement of their organizational routines, among other qualitative results. Keywords - Intervention; Dynamic Capabilities; Product Innovation Management; SMEs.
\end{abstract}

\title{
Referências
}

ACHANGA, P.; SHEHAB, E.; ROY, R.; NELDER G. Critical success factors for lean implementation within SMEs. Journal of Manufacturing Technology Management, v. 17, n. 4, p. 460-471, 2006. cross ref

AMBROSINI, V.; BOWMAN, C. What are dynamic capabilities and are they a useful construct in strategic management? International Journal of Management Reviews, v. 11, n.1, 29-49. 2009. crossref

AR, I. M.; BAKI, B. Antecedents and performance impacts of product versus process innovation: empirical evidence from SMEs located in Turkish science and technology parks. European Journal of Innovation Management, v. 14, n. 2, p. 172-206, 2011. crossref

ARMENAKIS, A. A.; BEDEIAN, A. G. Organizational change: A review of theory and research in the 1990s. Journal of management, v. 25, n. 3, p. 293-315, 1999. crossref

ASSARLIND, M.; ERIKSSON, H.; GREMYR, I.; JAKOBSSON, T. Adopting new ways of working in small and medium-sized enterprises: findings from interventions in 12 European companies. Total Quality Management \& Business Excellence, v. 24, n. 7-8, p. 945-958, 1 ago. 2013.

BAMFORD, D. R.; FORRESTER, P. L. Managing planned and emergent change within an operations management environment. International Journal of Operations \& Production Management, v. 23, n. 5, p. 546-564, 2003. crossref

BARCZAK, G.; GRIFFIN, A.; KAHN, K. B. PERSPECTIVE: Trends and Drivers of Success in NPD Practices: Results of the 2003 PDMA Best Practices Study*. Journal of Product Innovation Management, v. 26, n. 1, p. 3-23, 2009. crossref

BARNEY J. B; CLARCK, D. N. Resources-Based Theory: Creating and sustaining competitive advantage. UK: Oxford University Press. 2007.

BARNEY, J. B. Firm resources and sustained competitive advantage. Journal of Management, v. 17, n. 1.p. 99-120. 1991. cross ref

BEER, M.; NOHRIA, N. Cracking the Code of Change. Harvard Business Review, v. 78, n. 3, p. 133.2000.

BURNES, B. No such thing as... a "one best way" to manage organizational change. Management Decision, v. 34, n. 10, p. 11-18, 1996. crossref

BURNES, B. Managing Change: A Strategic Approach to Organisational Dynamics, 4th edn Harlow:Prentice Hall. 2004a.

BURNES, B. Kurt Lewin and the Planned Approach to Change: A Re-appraisal. Journal of Management Studies, v. 41, n. 6, p. 977-1002, 2004b. crossref

BURRell, G.; MORGAN, G. Social Paradigms and Organisational Analysis. London: Heinemann, 1979. 
BY, T.; R. Organisational change management: A critical review. Journal of Change Management, v. 5, n. 4, p. 369380,2005 . crossref

CARVALHO, F. M.; KAYO, E. K.; MARTIN,D. M. L. Tangibilidade e Intangibilidade na Determinação do Desempenho Persistente de Firmas Brasileiras. RAC, Curitiba, v. 14, n. 5, art. 6, p. 871-889, set./out. 2010.

CHECKLAND, P. Systems thinking, systems practice: includes a 30-year retrospective. 1999.

CHECKLAND, P.; HOLWELL, S. Action research: its nature and validity. Systemic Practice and Action Research, v. 11, n. 1, p. 9-21, 1998. crossref

CHENG L. C.; MELO FILHO, L. D. R. QFD: Desdobramento da Função Qualidade na Gestão de Desenvolvimento de Produtos. Editora blucher. $2^{\mathrm{a}}$ ed. p.539. 2010.

COOPER, R. G. Perspective: The Stage-Gate idea-to-launch process-update, what's new, and NexGen systems. Journal of Product Innovation Management, 25(3), 213-232. 2008. crossref

COOPER, R. G.; EDGETT, S. J. Maximizing productivity in product innovation: if it's time to take a hard look at the methods and systems you rely on to conceive, develop and launch new products, then these seven principles are a good place to start. Research-Technology Management, v. 51, n. 2, p. 47+, abr. 2008.

COOPER, R. G.; EDGETT, S. J.; KLEINSCHMIDT, E. J. Portfolio Management for New Products. Reading: Addison-Wesley Publishing. 230p. 1998.

COUGHLAN, P.; COGHLAN, D. Action research for operations management. International journal of operations \& production management, v. 22, n. 2, p. 220-240, 2002. crossref

CROSSAN, M. M.; APAYDIN, M. A Multi-Dimensional Framework of Organizational Innovation: A Systematic Review of the Literature. Journal of Management Studies, v. 47, n. 6, p. 1154-1191, 2010. crossref

DE BRENTANI, U. Innovative versus incremental new business services: different keys for achieving success. Journal of Product Innovation Management, v. 18, n. 3, p. 169-187, maio 2001. crossref

DONE, A.; VOSS, C.; RYTTER, N. G. Best practice interventions: Short-term impact and long-term outcomes. Journal of Operations Management, v. 29, n. 5, p. 500-513, jul. 2011. crossref

EISENHARDT, K. M.; MARTIN, J. A. Dynamic capabilities: what are they? Strategic Management Journal, v. 21, n. 10-11, p. 1105-1121, 2000. crossref

EISENHARDT, K.M. Building theories from case study research. Academy of Management Review, New York, v. 14, p. 532-50, 1989.

GARENGO, P.; BIAZZO, S. Unveiling strategy in SMEs through balanced scorecard implementation: A circular methodology. Total Quality Management \& Business Excellence, v. 23, n. 1, p. 79-102, 2012. cross ref

GONÇALVES, C.A.; COELHO, M.F.; SOUZA, E. M. VRIO: Vantagem competitiva sustentável pela organização. Revista Ciências Administrativas, Fortaleza, v. 17, n.3, p. 819-855, set./dez. 2011.

HELFAT, C. E. Know-how and asset complementarity and dynamic capability accumulation: the case of R\&D. Strategic Management Journal, v. 18, n. 5, p. 339-360, 1997. crossref

HITT, M. A., IRELAND, R. D., \& HOSKISSON, R. E. Strategic Management - Competitiveness and Globalization: Concepts and Cases. Thomson/South-Western. 7a ed. 2007.

HOSKISSON, R.E.; HITT, M.A.; WAN, W.P.; YIU, D. Theory and research in strategic management: swings of pendulum. Journal of Management, UK, v. 25, p. 417-456, 1999.

KAMINSKI, P. C. ; OLIVEIRA, A. C. ; LOPES, T. M. Evaluation of the real use of formal methodologies in the product development process in brazilian SMEs. Product (IGDP), São Carlos - SP, v. 3, n. 2, p. 157-164. 2005.

KAMINSKI, P. C. ; OLIVEIRA, A. C. ; LOPES, T. M. Knowledge transfer in product development processes: a case study in small and medium enterprises (SMEs) of the metal-mechanic sector from São Paulo - Brazil. Technovation. 2008 .

KIM, L. Da Imitação à Inovação. Campinas: Editora UNICAMP. Coleção Clássicos da Inovação. 2005.

KIM, S.-H., \& HUARNG, K.-H. Winning strategies for innovation and high-technology products management. Journal of Business Research, 64(11), 1147-1150. 2011. crossref

KOTTER, J. P. Leading change: Why transformation efforts fail. Harvard business review, v. 73, n. 2, p. 59-67, 1995. 
KUMAR, M.; ANTONY, J.; TIWARI, M. K. Six Sigma implementation framework for SMEs - a roadmap to manage and sustain the change. International Journal of Production Research, v. 49, n. 18, p. 5449-5467, 2011. crossref

LIN, H.; MCDONOUGH, E. F.; LIN, S.; LIN, C. Y. Managing the Exploitation/Exploration Paradox: The Role of a Learning Capability and Innovation Ambidexterity. Journal of Product Innovation Management. v. 30, n. 2, p. 262278,2013 . crossref

LOCKETT, A.; THOMPSON, S.; MORGENSTERN, U. The development of the resource-based view of the firm: A critical appraisal. International Journal of Management Reviews, 11(1), 9-28. 2009. crossref

MELO FILHO, L.D.R., CHENG L. C. QFD na garantia da qualidade do produto durante seu desenvolvimento - caso em uma empresa de materiais. Revista Produção. v. 17, n. 3, p. 604-624, Set./Dez. 2007.

MEYER, M. H. Revitalize Your Product Lines Through Continuous Platform Renewal. Research Technology Management, v. 40, n.2, p.17-28. 1997. crossref

MEYER, M. H.; DALAL, D. Managing platform architectures and manufacturing processes for nonassembled products. Journal of Product Innovation Management, 19(4), 277-293. 2002.

MEYER, M. H.; LEHNERD, A. P. The Power of Product Platforms. New York: The Free Press, 267p. 1997.

MILLES R.E.; SNOW C.C.; MEYER, A.D.; COLEMAN, H. J. JR. Organizational Strategy, Structure, and Process, American Management Review. July 546-562. 1978.

MONTOYA-WEISS, M. M.; CALANTONE, R. Determinants of new product performance: A review and metaanalysis. Journal of Product Innovation Management, 11(5), 397-417. 1994. crossref

MORAN, J. W.; BRIGHTMAN, B. K. Leading organizational change. Career Development International, v. 6, n. 2, p. 111-119, 2001. crossref

MORGAN, J. M.; LIKER, J. K. The Toyota product development system: integrating people, process, and technology. New York: Productivity Press, 2006.

NELSON, R. R.; WINTER, S. G. An evolutionary theory of economic change. Cambridge, Harvard University Press. 1982.

NICHOLAS, J.; LEDWITH, A.; PERKS, H. New product development best practice in SME and large organisations: theory vs practice. European Journal of Innovation Management, v. 14, n. 2, p. 227-251, 2011. cross ref

O’CONNOR, G. C. Major Innovation as a Dynamic Capability: A Systems Approach*. Journal of product innovation management, v. 25, n. 4, p. 313-330, 2008. crossref

OAKLAND, J. S.; TANNER, S. Successful change management. Total Quality Management and Business Excellence, v. 18, n. 1-2, p. 1-19, 2007. cross ref

OCDE - Organisation for Economic Co-operation and development.OECD Compendium II. on SME and Entrepreneurship Related Activities Carried Out By International and Regional Bobies, 2004.

PENROSE, E.T. The Theory of the Growth of the Firm. New York: Wiley. 1959.

PETTIGREW, A. Context and Action in the Transformation of the Firm. Journal of Management Studies, v. 24, n. 6, p. 649-670, nov. 1987. crossref

PETTIGREW, A. M. Context and Action in the Transformation of the Firm: A Reprise. Journal of Management Studies, v. 49, n. 7, p. 1304-1328, nov. 2012. crossref

PHAAL, R.; FARRUKH, C. J. P.; PROBERT, D. Roadmapping for Strategy and Innovation: Aligning Technology and Markets in a Dynamic World. [s.1.] University of Cambridge, Institute for Manufacturing, 2010.

PRAJOGO, D. I.; BROWN, A. Approaches to adopting quality in SMEs and the impact on quality management practices and performance. Total Quality Management \& Business Excellence, v. 17, n. 5, p. 555-566, jun. 2006. crossref

RAMMER, C.; CZARNITZKI, D.; SPIELKAMP, A. Innovation success of non-R\&D-performers: substituting technology by management in SMEs. Small Business Economics, v. 33, n. 1, p. 35-58, jun. 2009. crossref

RAPOPORT, R. N. Three dilemmas in action research. Human Relations, v. 23, n. 6, p. 499-513, 1970. crossref

SABRAGIA, R., STAL, E. Tecnologia e Inovação: Experiências de Gestão na Micro e Pequena Empresa. São Paulo. PGT, USP. 304 p. 2002. 
SARACENI, A. V.; JÚNIOR, P. P. DE A.; RESENDE, L. M. Proposta de Desenvolvimento de Inovação Tecnológica em Arranjos Produtivos Locais. Revista Gestão Industrial, v. 9, n. 1, 22 maio 2013. cross ref

SCHNAARS S. P. Managing Imitation Strategy: How Later Entrants Seize Markets From Pioneers. New York: Free Press. 1994.

SHAH, R. Lean manufacturing: context, practice bundles, and performance. Journal of Operations Management, v. 21, n. 2, p. 129-149, mar. 2003. crossref

SUSMAN, G. I.; EVERED, R. D. An assessment of the scientific merits of action research. Administrative science quarterly, p. 582-603, 1978. crossref

TEECE, D.J. Explicating Dynamic Capabilities : The Nature And Microfoundations Of ( Sustainable ) Enterprise Performance. Strategic Management Journal. 1350, 1319-1350. 2007. crossref

TEECE, D. J.; PISANO, G.; SHUEN, A. Dynamic capabilities and strategic Management. Strategic Management Journal, Vol. 18:7, 509-533. 1997. crossref

THIOLLENT, M. Pesquisa-ação nas Organizações. São Paulo: Atlas, 1997.

TIDD, J.; BESSANT, J. R.; PAVITT, K. Managing innovation: integrating technological, market and organizational change. [s.1.] John Wiley \& Sons Inc, 2005.

ULRICH, K. T.; EPPINGER, S. D. Product design and development. (5th ed). McGraw-Hill. 2012.

WESTBROOK, R. Action research: a new paradigm for research in production and operations management. International Journal of Operations \& Production Management, v. 15, n. 12, p. 6-20, 1995. crossref

WIT, B.; MEYER, R Strategy Process, Content, Context an international perspective. 4a. edition, UK: Centage Learning EMEA. 2010.

WOMACK, J. P.; JONES, D. T. Lean thinking: banish waste and create wealth in your corporation. New York: Free Press, 2003.

YIN, R.K. Estudo de Caso: Planejamento e Métodos. $3^{a}$ ed. Porto Alegre: Bookman, 2005.

YUSOF, S. M.; ASPINWALL, E. A conceptual framework for TQM implementation for SMEs. The TQM Magazine, v. 12, n. 1, p. 31-37, 2000. crossref

YUSOF, S. M.; ASPINWALL, E. Case studies on the implementation of TQM in the UK automotive SMEs. International Journal of Quality \& Reliability Management, v. 18, n. 7, p. 722-744, 2001. crossref

ZOLLO, M.; WINTER, S.G. Deliberate Learning and the Evolution of Dynamic Capabilities. Organization Science 13(3):339- 351. 2002. crossref

ZUBER-SKERRITT, O.; PERRY, C. Action research within organisations and university thesis writing. Learning Organization, The, v. 9, n. 4, p. 171-179, 1 out. 2002.

\section{Dados dos autores:}

\section{Nome completo: Leonel Del Rey de Melo Filho}

Filiação Institucional: Universidade Federal de Minas Gerais

Departamento: Faculdade de Ciências Econômicas

Função ou cargo ocupado: Doutorando do Programa do Centro de Pós-Gradução e Pesquisa em Administração (CEPEAD)

Endereço para correspondência: Rua Souza Menezes, 121, apto 406, Bloco B, Salgado Filho. Belo

Horizonte, MG. CEP: 30550-120

Telefone: $+55318733-5770$

e-mail: leoneldrmf@yahoo.com.br 


\section{Nome completo: Carlos Alberto Gonçalves}

Filiação Institucional: Universidade Federal de Minas Gerais (UFMG) e Fundação Mineira de Educação e Cultura (FUMEC)

Departamento: Faculdade de Ciências Econômicas

Função ou cargo ocupado: Professor Associado da UFMG e da FUMEC

Endereço para correspondência: Faculdade Ciências Econômicas Av. Antônio Carlos, 6627/ sala 4049.

Pampulha. Belo Horizonte- MG CEP 31270-901.

Telefone: + 5531 3409-7040 Fax: + 5531 3409-7054

e-mail: carlos@ face.ufmg.br

\section{Nome completo: Lin Chih Cheng}

Filiação Institucional: Universidade Federal de Minas Gerais

Departamento: Engenharia de Produção

Função ou cargo ocupado: Professor Associado

Endereço para correspondência: Departamento de Engenharia de Produção Av. Antônio Carlos, 6627 Pampulha. Belo Horizonte- MG CEP 31270-901

Telefone: + $55313409-4903$

e-mail: lincheng@ufmg.br

\section{Nome completo: Lauro Soares de Freitas}

Filiação Institucional: Universidade Federal de Minas Gerais

Departamento: Faculdade de Ciências Econômicas

Função ou cargo ocupado: Doutorando do Programa do Centro de Pós-Gradução e Pesquisa em Administração (CEPEAD)

Endereço para correspondência: Av. Antônio Abrahão Caram, 820, Sala 810 São José (Pampulha) Belo Horizonte/MG - CEP: 31275-000

Telefone: +55 31 9499-9897

e-mail: lauro_freitas@yahoo.com

Submetido em: 06/12/2013

Aceito em: 18/12/2014 